\title{
El viaje de Ilyās ibn al-qissīs Hannā 1-Mawșilì (Elías de Babilonia o de San Juan) a Europa y Nueva España en el siglo XvII
}

\author{
The journey of Ilyās ibn al-qissīs \\ Hannā 1-Mawșili (Elias of Babylon \\ or of Saint John) to Europe and \\ New Spain in the seventeenth century
}

\section{ARTURO PONCE GUADIAN*}

Resumen: El relato de viaje (rị̣la) de Ilyās ibn al-qissīs Hannā l-Mawșili (m. circa 1699) es la primera descripción en lengua árabe, conocida a la fecha, sobre la América hispana, escrita en tierras americanas en el siglo XVII, primero en Perú y luego en la Nueva España, y revisada en Sevilla al regreso del viajero a España. Se presenta un esbozo biográfico del viajero árabe; una relación del inicio de la larga travesía; una traducción del árabe al español de fragmentos relevantes del inicio del viaje desde Medio Oriente, el paso por Europa y la salida de España rumbo a América; una traducción de episodios relevantes del viaje a la Nueva España y el regreso a España y, por último, una cronología cuyo fin es aclarar algunos supuestos y errores en torno a la vida y el viaje de Elías de Babilonia.

Palabras clave: árabe; caldeos católicos; Medio Oriente; Europa; Nueva España.

Abstract: The travelogue (rị̣la) of Ilyās ibn al-qissīs Hannā l-Mawṣilī (dec. circa 1699) is the first known description in the Arabic language

Recepción: 18 de abril de 2017. / Aceptación: 25 de octubre de 2017.

* Universidad Michoacana de San Nicolás de Hidalgo, apguadian@colmex.mx 
of Hispanic America written in American lands in the seventeenth century, beginning in Peru and then in New Spain, and finally reviewed in Seville, when the traveler returned to Spain. This article offers a biographical sketch of this Arab traveler; a summary of the beginning of his long journey; a translation from the Arabic to Spanish of outstanding fragments of his departure from the Middle East, passing through Europe, and the travel to America via Spain; a translation of important episodes of his journey to New Spain and the return to Spain, and a chronology that aims to clarify some ideas and errors about the life and travels of Elias of Babylon.

Key words: Arabic; Chaldean Catholics; Middle East; Europe; New Spain.

\section{Introducción}

El relato de viaje de Elías de Babilonia, cuyo motivo oficial fue la búsqueda de limosnas para la Iglesia caldea, es la primera descripción en lengua árabe sobre la América hispana escrita en tierras americanas, primero en Perú y luego en la Nueva España. Hacia 1900 fueron descubiertos los textos manuscritos de don Elías por el jesuita libanés Anțūn Rabbāt (Antoine Rabbath, 1867-1913) en la Biblioteca del Arzobispado de Alepo de la Iglesia católica siriaca. Los manuscritos, en 369 páginas, incluyen el Relato de viaje (pp. 1-100) y Una bistoria de la conquista de América (214 pp.), ${ }^{1}$ y de la página 314 al final hay una traducción en árabe del relato de un enviado otomano a Francia. ${ }^{2}$ El relato de viaje (ribhla) ${ }^{3}$ de al-Mawsili fue editado por el padre Rabbāt en 1905 y 1906. ${ }^{4}$ En la British

${ }^{1}$ En realidad, los manuscritos contienen no sólo el primer relato en árabe sobre la América hispana, sino también la primera historia escrita en árabe sobre el Nuevo Mundo (Ghobrial, 2012, p. 1; Matar, 1999, p. 190).

${ }^{2}$ Véase una descripción del manuscrito en la edición del texto árabe (Rabbāt [ed.], 1906, p. 2), así como en la reproducción de la edición de 1905 (Al-Ŷarrāh, 2001, p. 135).

3 "La palabra riḅla nombra en árabe tanto el viaje en sentido genérico como el relato escrito de un viaje realizado por cualquier país del mundo. Es un término empleado en el habla diaria y también otro literario que designa un género concreto: la literatura de viajes" (Paradela, 2005, p. 1).

${ }^{4}$ El título de la primera edición del texto árabe en la revista Al-Machriq es Riḅla awrwal sā̉ih šarqī ilà Amrika [Rihla del primer viajero oriental a América] (Rabbāt [ed.], 1905). La segunda edición, publicada por la Imprenta Católica en Beirut, lleva 


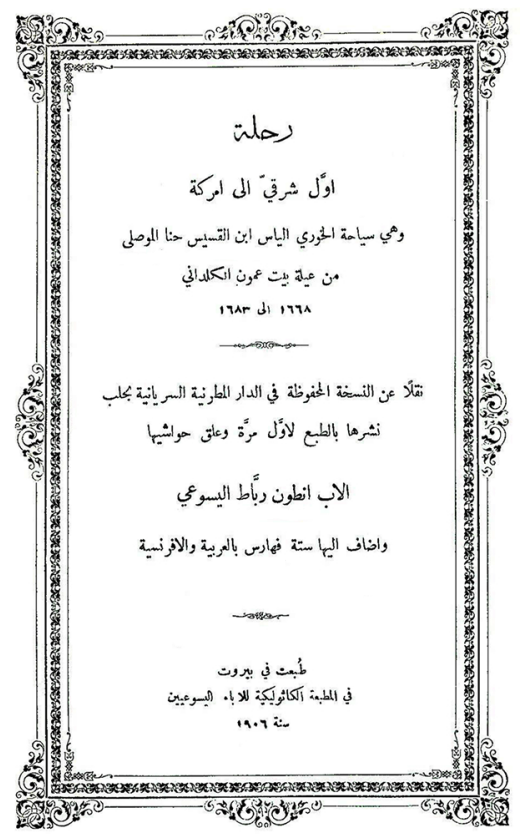

Portada de la edición de 1906 preparada por el jesuita Anțūn Rabbāt de la ribla del cura Elías, hijo del sacerdote Hannā l-Mawșilī, de la familia caldea 'Ammūn.

\section{Library hay un manuscrito que incluye sólo los dos primeros} textos. ${ }^{5}$ La riḥla fue editada por Nūrī al-Ŷarrāh en $2001^{6}$ con

por título Riḅla awrwal šarqī ilà Amrika, wa-hiya siyāha al-jūrì Ilyās ibn al-qissīs Hannā l-Maresili min 'ayla bayt 'Ammün al-kaldāni [Rihla del primer oriental a América, el viaje del cura Elías hijo del sacerdote Hannā l-Mawșilī de la familia caldea 'Ammūn] (Rabbāt [ed.], 1906).

${ }^{5} \mathrm{Al}$ respecto, Matar (2001, p. 48) señaló: "El otro manuscrito está en la British Library (MS Oriental 3537). Éste es un manuscrito posterior, comprado por Issa alRassam al 'hijo del diácono' en 1786. En él se incluye el relato de viaje, junto con el material traducido de fuentes españolas, pero no la visita del embajador otomano". Sin embargo, el arabista ruso Ignace Kratchkovsky (1963, p. 705) reveló que mucho tiempo después de publicada la edición de Rabbath "fueron descubiertos otros manuscritos del viaje de Ilyās al-Mawsilī no sólo en Mosul sino en Bagdad y El Cairo, incluso en la Biblioteca de la India Office en Londres". Para un resumen y estudio de esos manuscritos, véase Ghobrial (2012, pp. 263-269).

${ }^{6}$ Editada con el título Al-Dabab wa l-'ásîfa. Riḥla Ilyās al-Mareșili ilà Amīrkā. Aw- 
base en el texto publicado por Rabbāt en 1905. La traducción de las partes que incluyo está basada en estas dos ediciones del texto árabe.

Este artículo se divide en cinco partes. En el primer apartado se presenta un esbozo biográfico del viajero árabe Ilyās ibn al-qissīs Hannā l-Mawșilī (m. circa 1699) que esclarece algunos aspectos sobre su origen y su pertenencia étnica y religiosa. En el segundo se ofrece una relación del inicio de la larga travesía, de la que se destacan algunos momentos importantes. La tercera parte es una traducción del árabe al español de fragmentos relevantes del inicio del viaje, la travesía por Europa y la salida de España rumbo a América, con notas aclaratorias. La cuarta sección también es una traducción que selecciona partes relevantes del viaje a la Nueva España y el regreso a España. Por último, se incluye una cronología a fin de aclarar algunos supuestos y errores en torno a la vida y al viaje de Elías de Babilonia.

\section{Reseña biográfica de al-Mawṣilī}

El nombre de nuestro personaje es Ilyās ibn al-qissīs Ḥannā 1-Mawșilī (Elías hijo del sacerdote Juan de Mosul), como aparece registrado en las dos ediciones de su célebre relato de viaje, publicadas por el sacerdote jesuita Antoine Rabbath en 1905 y en 1906.

Sin embargo, en el colofón (escrito en árabe y en latín) del libro de oraciones (Horae diurnae et nocturnae ad usum Orientalium, 1692) ${ }^{7}$ que fue impreso en Roma con el patrocinio del

wal riḅla šarqiyya ilà l-'álam al-ŷadìd [El oro y la tormenta. El viaje de Ilyās al-Mawșilī a América. El primer viaje oriental al Nuevo Mundo] (Ŷarrāh [ed.], 2001). Véase la traducción francesa de esta edición (Jarrâh [ed.], 2011).

${ }^{7}$ Véase colofón publicado en Schnurrer (1811, pp. 256-260). En el texto del colofón (p. 257) se indica, de manera específica, que "ha sido impreso por el peculio y el sustento del sacerdote Elías" (qad țubi ‘hi min mälibi wa rizqibi al-qissìs Ilyās), como lo había hecho notar Kratchkovsky (1963, p. 703), por lo que resulta extraña la afirmación de Farah (2003, p. xvii) de que el libro en cuestión fue patrocinado por quien, en realidad, estuvo al cuidado de la edición, Andrāws ibn Maqdisī 'Abd Allāh (sobrino de Elías, que adoptó en España el nombre de Andrés de San Juan), lo cual se especifica en el texto mismo (Schnurrer, 1811, p. 258). Ghobrial (2014, p. 90) advirtió que Andrāws fue el asistente de su tío en esa ocasión. 


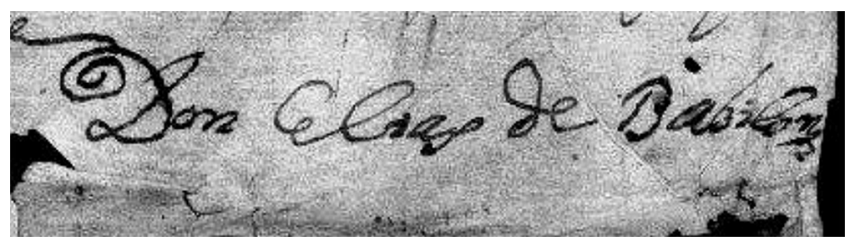

Firma de don Elías que aparece en una petición al rey incluida en la licencia para pasar a las Indias, 1675 (AGI, Contratación, leg. 5440, N. 2, R. 135).

Compárese con la firma de la siguiente imagen.

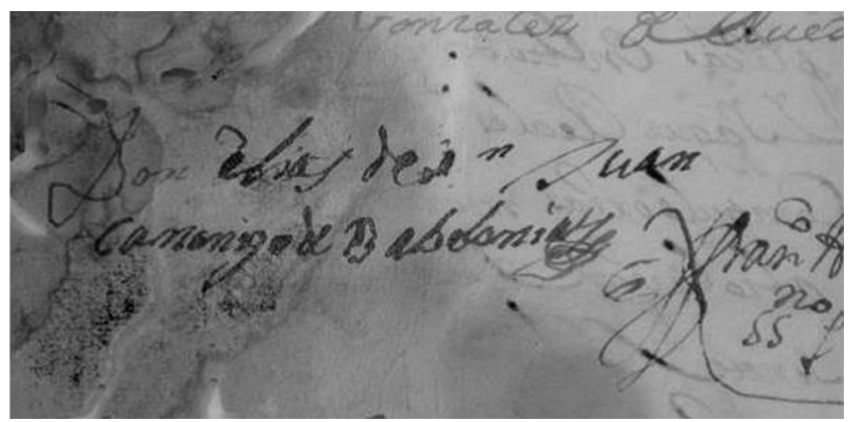

Firma contenida en un documento del Archivo Histórico Provincial de Cádiz, c. 1697, en el que aparece como don Elías de San Juan (Ghobrial, 2014, p. 92). Compárese con la firma de la imagen anterior.

mismo don Elías, aparece un dato que arroja luz sobre su lugar de nacimiento, pues se le menciona como "el sacerdote Elías [al-qissīs Ilyās], llamado el cura de Bagdad [jūrī l-Bagdādī], hijo del sacerdote Juan de Mosul [ibn al-qissīs Hannā l-Mawșilī]”. En los documentos españoles se le llamó Elías de Babilonia (de Bagdad) ${ }^{8}$ y Elías de San Juan (Hannā, Juan). ${ }^{9}$

${ }^{8}$ Un viajero francés del siglo XVII destacó en el relato de sus viajes la identidad entre Babilonia y Bagdad: "Babilonia que los turcos, árabes y persas llaman Bagdad", así como la importancia de la ciudad para los caldeos al titular el capítulo 55 de sus viajes: "Babylone ou Bagdat capitale de Kaldée" (Boullaye, 1657, p. 324).

${ }^{9}$ En la petición anexa a la licencia real, fechada en Cádiz el 3 de febrero de 1675, 
Esta referencia apoya la idea de que Elías era originario de Bagdad, no de Mosul, que sería la ciudad de nacimiento de su padre y el origen de su familia. Esto ya había sido expuesto por Nabil Matar al destacar que el nombre que aparece en la riḅla indica que la familia del canónigo era originaria de Mosul, pero en el texto del relato hay una referencia que hace pensar que él nació en Bagdad (Matar, 2003, p. 45). Elías, en el arreglo de una discordia en Chiapa, exclamó: “Aquí estoy, un cura que viene de la ciudad de Bagdad, haciendo la paz entre nosotros [ $h \bar{a}$ and $\bar{a}$ jūrī yā' min balad Bagdād li-yasliḅunā]" (Rabbāt [ed.], 1906, p. 62; Al-Ŷarrāh [ed.], 2001, p. 107).

Asimismo, en el colofón del libro de oraciones que mandó imprimir don Elías en Roma se menciona el nombre de la familia tribal a la que pertenecía: "de la familia 'Ammūn [ $\mathrm{min}$ 'ayla bayt 'Ammün]" (Horae diurnae et nocturnae ad usum Orientalium, 1692, en Schnurrer, 1811, p. 257), que corresponde al nombre que aparece en la portada de la edición de su riḅla, en 1906, y con la corrección que el mismo Rabbāt (1906, pp. 3 , 84) hizo en esa edición. Sin embargo, en la introducción de la edición de 1905 se menciona: "de la familia 'Ammūda" (AlŶarrāh [ed.], 2001, p. 133). Esta circunstancia ha motivado algunas confusiones sobre el nombre de la familia tribal de don Elías. ${ }^{10}$

aparece al final del documento la firma "Elías de Babilonia" (AGI, Contratación, leg. 5440 , N. 2, R. 135). Por otra parte, en la Nueva España se hace referencia a don Elías con el apellido De San Juan, como se asienta en el Acta del claustro pleno celebrado en la Real y Pontificia Universidad de México el 18 de julio de 1682 (AGN, México, Instituciones coloniales/Regio Patronato Indiano/Universidad [114], vol. 17). En ese documento se registra que se dio lectura de un memorial de "Elías de San Juan", canónigo de Babilonia, remitido por el virrey conde de Paredes en el que pedía una limosna "para el rescate de aquella santa Iglesia y de cuatro mil familias y veinte mil personas católicas que padecen de cruel opresión de los bárbaros mahometanos..."; se aprobó que se dieran 200 pesos (Carreño, 1963, vol. 1, pp. 298-299. Véase Ghobrial, 2014, p. 84). Asimismo, el oidor de la Real Audiencia de Lima, Diego Andrés Rocha, se refirió a él, en 1681, como "un canónigo de Babilonia, que está en la ciudad de los Reyes, nombrado D. Elías de San Juan...” (Rocha, 1891, p. 216; Taboada, 2011, p. 20).

${ }^{10}$ Farah (2003, p. Ix) llamó la atención sobre la ambivalencia del nombre cuando comentó que "el editor árabe usa la grafía $A$ mûda, pero también acepta que puede ser Amûna”; sin embargo, no aclaró que Rabbath había corregido la errata en la edición de 1906. Tampoco al-Jarrāh (2001, p. 10) aclara que Rabbāt hizo la corrección de la errata en la edición de 1906, pues señala que el autor del viaje era "de la familia 'Amûda, según Anțūn Rabbāt, o 'Amûn, según Kratchkovsky”. 
Investigaciones recientes han permitido tener más información acerca de la familia 'Ammūn, según las cuales ésta sería originaria del pueblo caldeo de Alqūšs, ubicado al norte de Mosul, ${ }^{11}$ que se convirtió en centro importante de la cristiandad en Medio Oriente después de que el monje nestoriano Hirmiz estableció un monasterio en las afueras de las montañas de Alqūšs, en el año 640 e.c. (Budge, 1902, parte 1, pp. xii-xiv). El lugar fue utilizado como sede de varios patriarcas de la Iglesia asiria de Oriente y de ese monasterio salió Yūhannā Sūlāqā (c. 1510-1555), quien decidió unirse a la Iglesia católica en 1553 y establecer así la Iglesia caldea para convertirse en el primer patriarca de la Iglesia católica caldea.

$\mathrm{Al}$ respecto, también en el libro de oraciones citado (Horae diurnae et nocturnae ad usum Orientalium, 1692, en Schnurrer, 1811, p. 257; Kratchkovsky, 1963, p. 702) se especifica que la familia 'Ammūn pertenecía a "la estirpe de los patriarcas orientales de la nación de los caldeos [min nasli l-batârika l-mušriqiyyin min tạa’ifat al-kaldāniyyin]". La familia 'Ammūn formó parte, pues, de ese grupo de cristianos caldeos que prefirieron vincularse a la Iglesia de Roma y a sus intereses misionales en Medio Oriente. En 1622, la Iglesia de Roma había decidido, a través del Colegio de la Propaganda de la Fe, instruir a candidatos nativos como misioneros, por lo que privilegió como enviados de Roma a los jóvenes educados provenientes de iglesias locales o "nacionales", como las iglesias siriacas, convertidas al catolicismo (Aboona, 2008, p. 73).

Éste sería el caso de al-Mawșilī, quien provenía de una familia de origen nestoriano y se convirtió al catolicismo. Este dato es revelado por el padre carmelita Giuseppe di Santa Maria (Girolamo Sebastiani), que conoció a don Elías en Bagdad y lo acompañó en su viaje de regreso a Roma el 10 de octubre de 1658, lo que indica que antes de 1668 ya había estado en Europa. ${ }^{12} \mathrm{El}$

${ }^{11}$ Al respecto, al-Jarrâh (2011, pp. 19-20) comentó: "Por otra parte, gracias al escritor iraquí asirio Sa'dî al-Mâlih, disponemos de nuevas informaciones sobre la familia del autor [...] La familia 'Ammûn es, según él, originaria del pueblo de Alqûsh, situado a unos cincuenta kilómetros al norte de Mosul”.

${ }^{12}$ Kratchkovsky (1963, p. 702) destacó que al-Mawșilī había estado en Roma más de una vez y que "una de sus visitas, la que hizo a ella en 1659, fue mencionada en un libro en italiano por un fraile carmelita que tenía un rango provincial en Malabar, suroeste de la India. Elías había reencontrado a este fraile más de una vez, ya sea 


\section{padre Giuseppe (Santa Maria, 1666, p. 141) comentó en su relato:}

Eso me hizo tomar la decisión de dejar el camino de la Mesopotamia y de recorrer con un guía el desierto, en compañía de los soldados, dos esclavos y un Casis Elías, primero nestoriano, después católico, sobrino del patriarca de aquella nación, quien pretendía pasar a Roma por su devoción y por otros intereses. ${ }^{13}$

Esta referencia es muy importante en varios sentidos. En primer lugar, permite aclarar las dudas respecto al origen religioso de la familia de al-Mawsilī al indicar que era nestoriano, no jacobita, como algunos investigadores habían supuesto. ${ }^{14}$ En segunda instancia, confirma el rango de la familia en esa comunidad religiosa, que pertenecía a la línea de sus patriarcas. Por último, revela que don Elías había hecho un viaje a Roma al menos diez años antes del que da cuenta en su relato de viaje, y que tenía vínculos e intereses con la Iglesia romana tras su conversión al catolicismo. Importa destacar que los vínculos

durante su viaje a Iraq o en el curso de sus visitas a Roma". El fraile al que alude el arabista ruso es, en efecto, el padre Giuseppe di Santa Maria, delegado apostólico en la región de Malabar.

${ }^{13}$ También el padre Giuseppe informó que Elías tenía dos hermanos: “Abdel Messia” y "Abdalla” (Santa Maria, 1666, p. 275; Santa Maria, 1672, pp. 228, 230; Ghobrial, 2014, pp. 77-78). En el "Prefacio" a la traducción francesa del viaje de don Elías, al-Jarrâh (2011, p. 20) resumió esos vínculos familiares así: "Los dos hermanos de Elías fueron dignatarios de la Iglesia nestoriana, el mayor, 'Abd al-Masîh, en Bagdad, y el menor, 'Abdallah, en Mosul. Su tío Iliyyâ, y después su sobrino Yûhannâ, habían ocupado la función prestigiosa de patriarcas nestorianos, de 1627 a 1700”. Lo que no se sabía con claridad es que don Elías y su familia dieron origen al apellido De San Juan, que tuvo un papel importante en el empleo del turco otomano y de las lenguas semíticas, así como en la creación del arabismo en España, pues los hijos de sus hermanos 'Abd al-Masīh y 'Abd al-Allāh fueron intérpretes de "lenguas orientales" en la Secretaría de Estado y en la Biblioteca Real de Madrid: Abdel (Abel) Messi (entró en funciones como traductor de turco, árabe, siriaco y caldeo en la Secretaría de Estado en 1680); Isaac de San Juan (entró en funciones en 1698); Andrés de San Juan (Andrāws ibn 'Abd Allāh, entró en funciones en 1700 como intérprete de turco, árabe, siriaco y caldeo en la Secretaría de Estado) y su hijo Cristóbal de San Juan (en funciones en 1738); Juan Amón de San Juan, sobrino de Andrés de San Juan, entró en funciones como escribiente de la Biblioteca Real en 1754 (Gemayel, Saadé y Khater, 1998 pp. 2-3; Cáceres Würsig, 2000, pp. 257, 442-446).

${ }^{14}$ Por ejemplo, Farah (2003, p. X) comentó: "No está claro si el reverendo alMûsili usó la versión jacobita o nestoriana [en los servicios litúrgicos]. Al juzgar por el hecho de que el manuscrito fue descubierto en un monasterio localizado en el centro de la zona jacobita, podemos con seguridad asumir que ésta fue su afiliación religiosa”. 
de don Elías no sólo eran de carácter misional, también tenían una motivación económica y política, como se sugiere a lo largo de su relato, al estar vinculado a dignatarios religiosos y políticos de Italia, Francia y España.

\section{PRONOSTICO}

DE VN TVRCO MVYSABIO,

Y GRANDISSIMO ASTROLOGO;

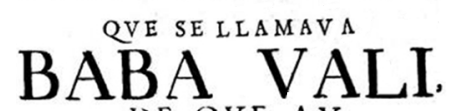

DE QVE AY

MVCHAS OPINIONES QVE MVRIO Chriftiano, hallado en vn Libro, efcrito en Lengua Turca, que trata de cifferentes Hiftorias, efcrito el áno 1012 .de la venida de Mahoma, que correfponde el de r604.de nueltra Redencion.

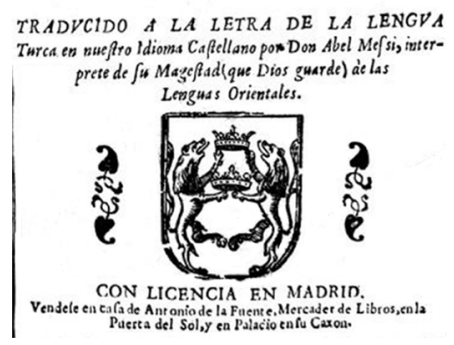

Portada de la traducción del turco al castellano por Abel Messi de un Pronóstico impreso en Madrid, 1689?

To Don Andrès de S. Fuan, Cavallero del Orden de S. Fuan, de la Efpuela de Oro, Interprete de las Lenguas Orientales de $\int u$ Mrgeftad, ( que Dios guarde) por Ju Secretaria de Eftado, y Gracia, y del Supreneo Confejo de la Santa, $y$ General Inquificion, oc, be traducido lo arriba referido de fu Original;y paraque confte lo firme en Madrid en 22. de Marzo de 1738 . Don Andrès de San Fuan.

Certificación de don Andrés de San Juan a la traducción del turco al castellano de una carta del bey de Argel para el padre general de la Merced, fraile Francisco Salvador Gilaberte, en relación con el rescate de cautivos cristianos, incluida en el Cántico de Débora, sermón del fraile Jacinto de Mendoza, Madrid, Convento de la Merced, 1738. 


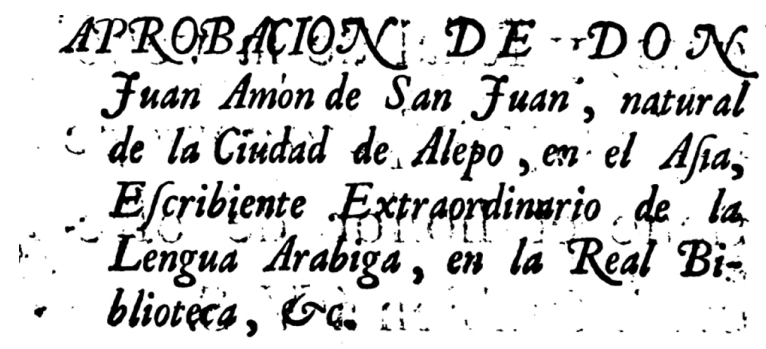

Encabezado de la aprobación dada en Madrid el 12 de febrero de 1761 por Juan Amón de San Juan (escribiente de la lengua árabe en la Biblioteca Real de Madrid) a la traducción del doctor Mariano Pizzi del texto apócrifo

Tratado de las aguas medicinales de Salam-Bir, Madrid, 1761. Este Juan Amón, como ya se mencionó, fue sobrino de Andrés de San Juan, y conservó entre sus apellidos el nombre 'Ammūn (Amón), de la familia tribal de la que descendía don Elías, quien fue conocido en España y Nueva

España como Elías de Babilonia o Elías de San Juan.

El itinerario de una larga travesía

El mismo al-Mawșilī narró que salió de Bagdad en 1668 para visitar el santo sepulcro en Jerusalén, y pasó por Damasco. Después de Jerusalén regresó a Damasco y se dirigió a Alepo para embarcarse en el puerto de Iskenderun (Alejandreta, en la actual Turquía) rumbo a Europa. Hizo escala en Chipre, Creta y Zante antes de arribar a Venecia.

Después de permanecer en cuarentena, estuvo 20 días en la ciudad de Venecia, luego marchó a Roma, donde pasó seis meses. Durante esa estancia, recibió del papa Clemente IX las cartas de presentación para su recorrido por las cortes europeas.

En seguida se dirigió a Francia, y pasó por Florencia, Livorno, Génova y Marsella. De Aviñón se dirigió a Lyon, donde se reencontró con el excónsul de Francia en Alepo, François Picquet. En París realizó una importante actividad, fue recibido por el rey Luis XIV y visitó a los duques de Orleans y de Saint-Aignan. Permaneció ocho meses en París y conoció a 
Solimán Aga, enviado otomano ante el rey de Francia, a quien sirvió como intérprete.

Decidió dirigirse a España, pasó por Orleans, Poitiers y Bordeaux; cruzó por Fuenterrabía y se encaminó a Madrid por San Sebastián y Burgos, donde visitó varios monasterios. En Madrid fue recibido por la regenta Mariana de Austria, a quien le entregó las cartas del papa Clemente IX y ella, en repuesta, le concedió una orden para que los virreyes de Sicilia y Nápoles le entregaran cada uno mil piastras.

Con el objetivo de recoger el dinero que se le había prometido, partió de Madrid hacia Italia. Pasó por Aragón y llegó a Zaragoza, donde se reunió con don Juan de Austria, el hermano del rey. En Barcelona se embarcó en un navío español, bloqueado 25 días en Cadaqués, y luego hizo escala en Tolón, para llegar finalmente a Roma. Se dirigió a Nápoles y Palermo, pero su viaje resultó infructuoso, pues no recibió el dinero prometido. Frustrado, retomó el camino de regreso a España vía Roma.

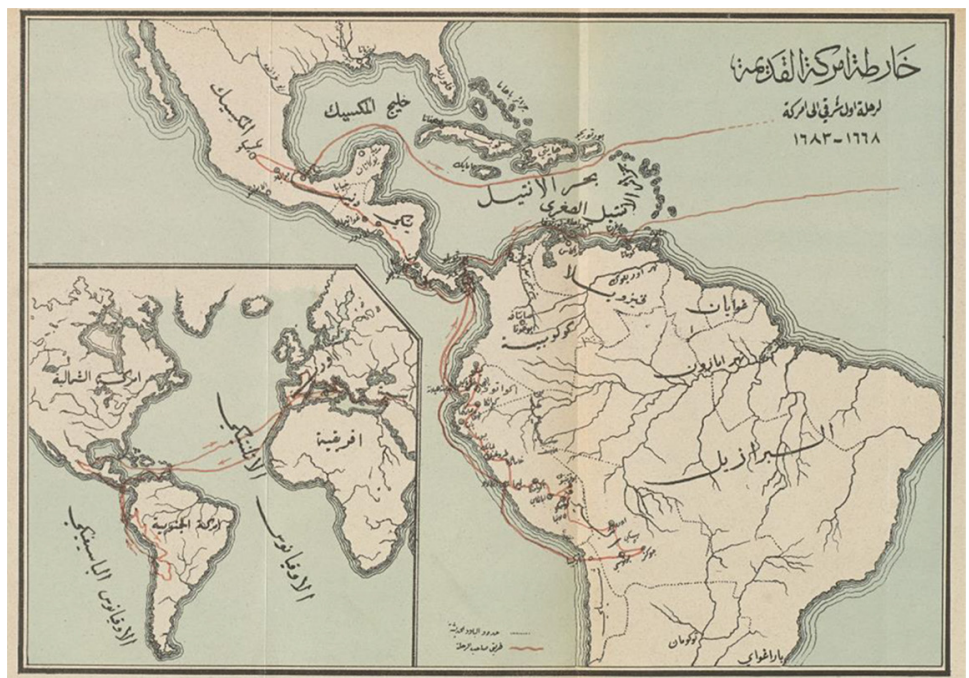

Mapa de la América antigua de la Ribla del primer oriental a América (incluido en la edición árabe impresa en Beirut: Rabbāt [ed.], 1906). 


\section{Salida de Bagdad, travesía por Europa y salida de Cádiz rumbo a América}

A continuación, se presenta la traducción del relato que hace don Elías del inicio de su viaje, desde su salida de Bagdad, así como su paso por Europa, hasta su partida de Cádiz rumbo a América.

\section{De Bagdad a Venecia ${ }^{15}$}

Yo, el más humilde de los sacerdotes, digo que salí de la ciudad de Bagdad el año del Señor Jesucristo de mil seiscientos sesenta y ocho con la intención de visitar el sepulcro de Cristo en compañía del jefe de artillería [topçi başi], llamado Mījā'îl $\bar{A} g \bar{a} .{ }^{16}$

Después viajamos por un paraje desolado y a medio camino salieron a nuestro encuentro alrededor de cien ladrones que se precipitaron sobre nosotros y nos dieron una batalla, pero triunfamos sobre ellos. Esto sucedió el día de la Fiesta de Resurrección ['Id al-Qiyāma]. Nosotros sólo éramos doce personas; sin embargo, con el poder de los instrumentos de guerra como los mosquetes [tufenk], logramos vencerlos.

A partir de aquí continuamos nuestro camino y viajamos a la ciudad de Damasco [madīnat al-Šam]; de Damasco me dirigí a la noble Jerusalén [al-Quds al-Šarīf) y fui ennoblecido con el viaje a esos lugares santos.

Después fui a la ciudad de Alepo y luego de algunos días descendí al puerto marítimo que se llama Alejandreta [Iskandarūna]; desde ahí abordé un barco inglés y viajamos con dirección a tierras de Europa.

Pasamos a la isla de Chipre y ahí visité la tumba de san Lázaro y sus hermanas María y Martha. De esta isla partimos

${ }^{15}$ Al-Ŷarrāh (ed.), 2001, p. 33-34; Rabbāt (ed.), 1906, pp. 4-5.

16 "Se trata de Michel Condoleo, jefe o comandante de la artillería otomana en Siria, Alepo y Bagdad, que había nacido en Creta y vivía en Damasco. Por orden del gobierno imperial, recorría la región para inspeccionar las condiciones de los depósitos de artillería. Los misioneros lo han mencionado frecuentemente en su correspondencia a causa de su firmeza en la religión católica y en la vida cristiana, ha sido su más ferviente partidario y les ha otorgado ayuda material y cultural” (Rabbāṭ [ed.], 1906, p. 4, n. 1). 
y, después de unos días, pasamos a la isla de Quraytišs, conocida como Creta. De ahí llegamos a isla de Zante, que es gobernada por Venecia, con otras dos islas cercanas a ella, llamadas Corfú y Cefalonia. Las dos son gobernadas por Venecia, llamada por los turcos Venedik y conocida en todo el mundo. De ahí partimos.

\section{En Venecia ${ }^{17}$}

Después de unos días, llegamos al puerto de la mencionada Venecia. Habían pasado sesenta días, que permanecimos en el mar, desde que salimos de Alejandreta hasta que arribamos a este puerto. Salimos del barco y después nos alojaron en la casa de la purificación llamada Nazaret en lengua italiana. Permanecimos ahí cuarenta y un días como es lo establecido. Este Nazaret está fuera de la ciudad, pues ésa es la costumbre en los países cristianos por temor a la peste. Al cumplirse los cuarenta y un días, el médico en jefe [ḥakim bāš̀ $]$ vino a examinarnos para ver si alguno de nosotros estaba enfermo. Después de eso nos dieron un permiso para que abandonáramos el Nazaret, salimos y entramos a la mencionada ciudad, permanecí allí veinte días paseando y visitando sus iglesias.

La riqueza que vi en la iglesia del evangelista san Marcos es una cosa indescriptible. Luego de algunos días ahí, me dirigí a la gran ciudad de Roma, donde permanecí seis meses. Visité los lugares santos, especialmente la basílica del apóstol san Pedro, única en el mundo por su belleza. Después salí para dirigirme al país de Francia, y pasé por la tierra de un príncipe llamado gran duque de Toscana, ${ }^{18}$ que vive en la ciudad de Florencia. Este príncipe es muy rico en dinero y posesiones. De Florencia me dirigí al puerto, hacia la ciudad llamada Livorno, gobernada por el mencionado príncipe. Después de pocos días, viajé al puerto de la ciudad de Génova, gobernada por un príncipe de manera autónoma. Esta ciudad se distingue por sus construcciones y su riqueza monetaria.

${ }^{17}$ Al-Ŷarrāh (ed.), 2001 pp. 35-36; Rabbāt (ed.), 1906, pp. 5-6.

${ }^{18}$ Fernando II de Médici (1610-1670), quinto gran duque de Toscana entre 1621 y 1670. Hijo de Cosme de Médici y de María Magdalena de Austria. 


\section{Viaje a Francia ${ }^{19}$}

De ahí también partí por mar y llegué al puerto de la ciudad de Marsella, gobernada por Francia. Después salí por tierra y marché a la ciudad de Aviñón, que está bajo el gobierno de nuestro señor el papa. Esta ciudad está en Francia, pero los antiguos reyes de este país la habían donado, con otras aldeas, a la Iglesia de San Pedro. De aquí transitamos por el río en una barcaza que era jalada a contracorriente por caballos. Llegamos a la ciudad de Lyon, que es una de las más grandes de Francia después de París, la ciudad del rey de Francia. Después me reuní con un hombre santo llamado el señor Picquet. ${ }^{20}$ Este noble hombre fue anteriormente cónsul en Alepo y, después de regresar de ese lugar, fue nombrado obispo de la ciudad de Bagdad; murió en Persia, en la ciudad de Hamadán, pero no tenemos tiempo para hablar de sus virtudes y de su vida edificante.

\section{En la corte del rey ${ }^{21}$}

Después de algunos días, salí de Lyon y me dirigí a la ciudad de París, sede del rey de Francia. Entré a la ciudad y fui a visitar al victorioso rey Luis, ${ }^{22}$ quien me recibió generosamente. Luego visité a su hermano, el duque de Orleans, ${ }^{23}$ a quien le presenté

${ }^{19}$ Al-Ŷarrāh [ed.], 2001, pp. 36-37; Rabbāt [ed.], 1906, pp. 6-7.

${ }^{20}$ François Picquet (1626-1685), cónsul de Luis XIV en Alepo de 1652 a 1662, y embajador extraordinario ante el shah de Irán en 1681. Después, en 1683, fue nombrado obispo de Babilonia (Bagdad) (Rabbāt [ed.], 1906, p. 6, n. 3). Elías mantuvo una estrecha relación con este importante personaje en Medio Oriente. El referido padre Santa Maria informó que ya estando para zarpar en 1658, "el casis Elías fue llamado a Alepo por el cónsul de Francia para enviarlo a Marsella y después a Roma” (Santa Maria, 1666, 268). El cónsul Picquet fue un elemento decisivo para vincular directamente los intereses económicos y políticos de Francia en el Imperio otomano con la causa misional católica (Masters, 2001, p. 82).

${ }^{21}$ Al-Ŷarrāh [ed.], 2001, p. 37; Rabbāt (ed.), 1906, p. 7.

${ }^{22}$ Luis XIV (1638-1715), el Rey Sol, rey de Francia y de Navarra de 1654 hasta su muerte. Hijo primogénito de Luis XIII y de Ana de Austria, hija del rey Felipe III de España. Casado con María Teresa de Austria (1638-1683), hermana del rey Carlos II de España, apodado el Hechizado.

${ }^{23}$ Felipe I (1640-1671), duque de Orleans, segundo hijo de Luis XIII y de Ana de Austria. Había establecido en París el proyecto de educar a jóvenes franceses para las misiones en Oriente Medio. 
como regalo una espada y celebré misa para él en la capilla de su palacio. Él me colmó de honores con amplia generosidad.

Mientras yo estaba ahí [París], un mensajero del sultán Muhammad Jān ${ }^{24}$ llegó para ver al rey Luis. Este mensajero es llamado en las lenguas turca y persa ilçi [enviado]; ${ }^{25}$ yo fui a visitarlo varias veces a causa de la lengua turca, después me pidió que permaneciera en París, así que no partí y me quedé ocho meses ahí.

\section{Paso por Burgos y hallazgo de la tumba de un rey armenio ${ }^{26}$}

Cruzamos el río y llegamos a un castillo bajo el dominio de España llamado Fuenterrabía, cercano a un poblado pequeño que se llama Irún, y de aquí me dirigí a un pueblo conocido como San Sebastián, que es un puerto en el Mar Occidental. Desde aquí viajé por tierra a Madrid, sede del rey de España, y pasé por un pueblo llamado Burgos. Aquí, visité un convento de monjes agustinos en cuya capilla había un altar con una cruz del Señor Jesucristo, llamado en lengua española [al-lisān al-sabanyūlì] Cristo de Burgos, que hace surgir muchos milagros. Ahí, también, vi en un convento de monjas la tumba del rey armenio de $\mathrm{Sis},{ }^{27}$

${ }^{24}$ Mehmet IV (1648-1687); durante su gobierno (1648-1687) intentó en varios momentos restablecer la alianza franco-otomana enviando a diferentes emisarios a París (Faroqhi, 2005, p. 73).

${ }^{25}$ En el texto árabe no aparece el nombre del enviado, pero se trata de Solimán Aga Muteferriqa, que llegó a Tolón el 4 de agosto de 1669 con un mensaje del sultán Mehmet IV para el rey Luis XIV, quien lo recibió en París el 5 de diciembre de 1669 (Rabbāt [ed.], 1906, p. 8, n. 1). El relato de la recepción apareció en la Gazzette de París ("L'Audiance donnée par Sa majesté, a Soliman Mouta-Faraca, Envoyé du Grand Seigneur”, 1669, pp. 1193-1200). Las circunstancias de esa misión diplomática dieron origen a la conocida obra El burgués gentilhombre de Molière, según lo relató Laurent d'Arvieux (1635-1702), intérprete y diplomático francés al servicio de la corte de Luis XIV (D’Arvieux, 1735, pp. 252-254; Armiño, 2015, pp. 51-55).

${ }^{26}$ El subtítulo es agregado mío (Al-Ŷarrāh [ed.], 2001, p. 40; Rabbāt [ed.], 1906, p. 9).

${ }^{27}$ Capital del reino de Cilicia: "Así es como lo hace nuestro geógrafo armenio «La Cilicia, dice él, es Sis y las provincias que confinan en Asia», quiere decir probablemente la Isauria. Los extranjeros, así como los árabes y los siriacos, le dan también a la Cilicia el nombre de su capital. Aboulfaradje dice con claridad «Bilad al-Sis o Bilad Sis». El catolicós Gregorio Degha ha agregado la terminación ouan, quizá para la rima de sus versos y ha hecho Sissouan. Así es como él escribe «Del monte Taurus, entrarán en el país de Sissouan»" (Alishan, 1899, p. 41; Mutafian, 1988). 
que se llamó Ovānīsī Tākāa, ${ }^{28}$ así como una inscripción funeraria en lengua armenia.

\section{En la corte del reino de España ${ }^{29}$}

Desde aquí [Burgos] continué el viaje y pasé por incontables ciudades, hasta que llegué a Madrid, sede del rey. En ese entonces estaba gobernando la reina, esposa del rey Felipe IV, puesto que el rey había muerto y dejó como sucesor a un hijo menor llamado Carlos II. ${ }^{30}$ Yo le presenté a la reina las cartas del papa Clemente IX $^{31}$ y ella ordenó que me dieran mil piastras del gobernador de Sicilia y otras mil piastras del gobernador de Nápoles. Así, obtuve de su mano una orden para recoger el dinero.

Salí de Madrid en dirección a la tierra de Italia a través de la provincia de Aragón [Arākūn], y pasé por un pueblo llamado Zaragoza [Sarākūzā], donde los reyes de España eran coronados en ese tiempo y donde juraban preservar y gobernar con las leyes antiguas. Ahí vi al hermano del rey, don Juan de Austria, ${ }^{32}$ que era hermano natural de él, a quien visité y fue muy generoso conmigo. Después partí y me dirigí hacia el mar y llegué a una ciudad llamada Barcelona, el puerto de la provincia de Cataluña en el mar oriental. De ahí viajé con los barcos del rey de España y después de dos días llegamos al puerto de

${ }^{28}$ En armenio, Hovhannes Takavor, 3nцhuduku fuuquinn, rey Juan. Esta referencia a un rey armenio muestra el interés y la relación que mantuvo Elías con los armenios, especialmente católicos, en Medio Oriente y Europa. ¿Acaso don Elías se refería en realidad a León V (1342-1393)? Último monarca latino del reino armenio de Cilicia que llegó a Madrid en 1384 y falleció en París, donde fue sepultado en el convento de los celestinos. Actualmente, su cenotafio se encuentra en la basílica de Saint Denise (Fradejas, 2012).

${ }^{29}$ Al-Ŷarrāh (ed.), 2001, p. 40; Rabbāt (ed.), 1906, p. 9.

${ }^{30}$ Carlos II de Habsburgo (1661-1700), hijo de Felipe IV (m. 1665) y de Mariana de Austria, quien fue regente de 1665 a 1675.

${ }^{31}$ Clemente IX (Giulio Rospigliosi, 1600-1669) fue papa de 1667 a 1669. Uno de los principales objetivos del viaje de don Elías a Europa, así como de su travesía a América, fue pedir limosna para la Iglesia caldea en Mesopotamia.

32 Juan José de Austria (1629-1679), hijo extramarital del rey Felipe IV, pero reconocido formalmente por él en 1642, fue un hábil político y militar, virrey de Sicilia y de Cataluña, así como gobernador de los Países Bajos. A la muere del rey Felipe IV se opuso a la regencia de la reina madre, Mariana de Austria. 
Cadaqués, donde el coral es extraído. Permanecimos ahí veinticinco días a causa de lluvias torrenciales en el golfo de Lyon y lo difícil de navegar ese paso muy peligroso.

\section{Salida de Tolón para Roma y encuentro con su sobrino ${ }^{33}$}

Después de un tiempo, celebramos misa en la mañana del domingo, nos preparamos para navegar, partimos y viajamos. Luego de un día y una noche, llegamos al puerto de Tolón, gobernado por Francia. Desde ahí viajé a Roma y visité al hijo de mi hermano, el diácono [al-šamās $]$ Yunān, ${ }^{34}$ que había concluido sus estudios y se disponía a salir de Roma para regresar a su país, después de que la Sagrada Congregación [al-Maŷma' al-Muqaddas $]^{35}$ lo proveyó de libros y otras cosas necesarias.

\section{Viaje infructuoso $0^{36}$}

De ahí llegué a Nápoles y presenté la orden de la reina a su ministro [wazìr] que gobierna allí, a quien se le dice virrey. Éste la leyó y me contestó así: "Ve a Sicilia [Sīsìlya] y consigue las mil piastras". Viajé a la isla de Sicilia y llegué a la ciudad que se llama Palermo, donde está el ministro de la reina [wazir al-mali$k a$ ] que gobierna, al que se le llama también virrey [vì l-ray]. Le presenté a él la orden que me concedía mil piastras y me prometió que me las daría, pero después de dos meses me dijo: "No puedo dártelas". Luego, desde ahí, envié a Alepo al diácono Yūnān, hijo de mi hermano.

Cuando comprendí que no tenía esperanza de obtener las mil piastras de ese corazón duro, después de lo cansado que había sido para mí el viaje, regresé a Nápoles con el fin de recoger p. 10).

${ }^{33}$ El subtítulo es agregado mío (Al-Ŷarrāḥ [ed.], 2001, p. 41; Rabbāt [ed.], 1906,

${ }^{34}$ En el texto árabe, Yūnān, que conserva el nombre Jonás en siriaco (Yawnān), del hebreo Yōnah, en árabe, Yūnus.

${ }^{35} \mathrm{La}$ expresión árabe traduce el nombre de la institución católica Sacra Congregatio de Propaganda Fide (Sagrada Congregación para la Propagación de la $\mathrm{Fe})$, fundada en 1622 por el papa Gregorio XV.

${ }^{36}$ Al-Ŷarrāḥ (ed.), 2001, pp. 41-42; Rabbāṭ (ed.), 1906, p. 10. 
las otras mil piastras del virrey, como me lo había prometido, pero éste me contestó: "Si el gobernador de Sicilia no te dio las mil piastras, yo tampoco te daré nada, pues no tengo dinero".

Entonces, con la esperanza perdida, volví a España para devolverle a la reina su orden. Regresé vía Roma y el puerto de Livorno, donde abordé un barco para llegar a la ciudad de Barcelona y de allí a Zaragoza, donde vi al hermano del rey y le informé lo que me había sucedido en cuanto a fatigas y pérdidas, pues había invertido cuatrocientas piastras de ida y vuelta. Se afligió de esto. Me había acompañado sirviéndome un cristiano de Alepo [rūmī min aulād Ḥalab], llamado Yūsuf [José] al-Fattāl.

\section{En Portugal ${ }^{37}$}

Regresé a Madrid y expuse mi situación a la reina, que se molestó mucho, pues sus órdenes no habían sido cumplidas. Luego de que le entregué sus órdenes, salí de Madrid para dirigirme a tierras de Portugal.

Permanecí en esas tierras siete meses y visité todas sus iglesias y monasterios. Algunos habitantes de ese país son muy generosos y católicos de fe. También se encuentran aquí cristianos nuevos conversos de religión judía, son conocidos por todos y no se casan con cristianos viejos; algunos de ellos, en realidad, reniegan de la religión de Cristo. Pero cuando se verifica que ellos actuaron así, son juzgados por el Consejo de la Fe [Dīwān al-Imān] o Santa Inquisición y condenados al fuego. En esta ciudad de Lisboa hay un puerto marítimo y de aquí zarpan los barcos hacia la India Oriental [Hind al-Šrq], a la tierra de Goa, que es gobernada por Portugal.

\section{Una sorpresa ${ }^{38}$}

Después de que permanecí allí [en Portugal] siete meses, regresé a la ciudad de Madrid y me hospedé en la residencia de un 
noble llamado el duque de Aveyro, ${ }^{39}$ de este hombre y de sus amigos recibí una generosa ayuda. Una de las damas, llamada la marquesa de los Vélez, ${ }^{40}$ que era la aya del rey, me hizo grandes honores y le solicitó permiso al rey para que yo celebrara misa ${ }^{41}$ para él. Tenía conmigo, entonces, a un diácono de rito griego [rümī,$^{42}$ a quien le había enseñado a servir en misa. Entré a la iglesia del rey y celebré la misa ante él y su madre. Después de eso, la reina ordenó a la institutriz del rey que me preguntara si deseaba algo como recompensa. Le pedí un tiempo para pensar y me dirigí hacia algunos amigos para que me aconsejaran, y ellos me dijeron que pidiera una licencia y una cédula real para ir a tierras de la India Occidental [Hind al-Garb]. ${ }^{43}$ Éste fue un

${ }^{39}$ Manuel Ponce de León y Fernández de Córdoba (1633-1693), I duque de Aveyro, casado con María de Guadalupe de Lencastre y Cárdenas Manrique (1630-1715), I duquesa de Aveyro, quien era pariente de María Luisa Manrique de Lara y Gonzaga (1649-1729), condesa de Paredes y marquesa de la Laguna, esposa de Tomás Antonio de la Cerda (1638-1692), marqués de la Laguna y conde de Paredes, virrey de Nueva España de 1680 a 1686.

${ }^{40}$ Engracia Álvarez de Toledo (1623-1686), V marquesa de los Vélez.

${ }^{41}$ El 22 de abril de 1673, un sacerdote caldeo llamado "Dom Hissa" (La sainte messe des Caldéens, 1678) había celebrado misa en siriaco en la capilla del castillo de Saint Germain en Laye, Francia, ante la reina María Teresa (Ghobrial, 2014, p. 83), hermana del rey Carlos II de España y esposa del rey Luis XIV de Francia. La reina ordenó después traducir la misa al francés y publicarla. En el texto francés se incluye sólo una dedicatoria a la reina del traductor francés, el abad Morel, en la que se menciona que Dom Hissa es un sacerdote caldeo de la villa de Nínive (en las afueras de Mosul, actual Iraq). De esa versión francesa se hizo una traducción al castellano ( $\mathrm{La}$ santa missa de los caldeos, 1679), que incluye una dedicatoria del sacerdote caldeo Don Hissa al rey Carlos II, en la cual el sacerdote declara que él es el traductor al castellano y se presenta como capellán del rey. Sin embargo, la segunda edición castellana ( $\mathrm{La}$ santa missa de los caldeos, ¿1701?) resulta muy reveladora para conocer algunos datos del sacerdote caldeo y su relación con don Elías. Esta edición incluye una dedicatoria del sacerdote caldeo D. Issa ('Īsà) al rey Felipe V (reinó 1700-1746), en la que se presenta como su capellán y sostiene haber celebrado la misa caldea ante el rey y su esposa, la reina María Luisa de Saboya (reina 1701-1714); resalta su feliz estancia en Madrid, "por residir en ella mi hijo Abel Missi, empleado por más de diez y seis años (hasta su fallecimiento en el real servicio, traductor de los idiomas arábigo, turquesco, caldeyco y syriaco)". Abel Messi, como mencioné, era primo de Andrés y de Isaac de San Juan (Cáceres Würsig, 2000, p. 474) y fue el primero de los parientes de don Elías en ocupar el cargo de traductor en la Secretaría de Estado de España desde 1680 hasta su muerte en 1698. De manera que don Elías, como su pariente don Issa, había recorrido Europa en actividades misionales vinculado al Colegio Propaganda Fide con apoyo de los reinos de Francia y España.

${ }^{42}$ Se trataría del rito griego melkita, es decir, católico, pues los miembros del rito griego ortodoxo eran considerados herejes y cismáticos, por lo tanto, perseguidos por la Inquisición.

${ }^{43}$ Hind al-Garb (India del Occidente) es la versión árabe de la expresión "Indias 
asunto difícil para mí, pero yo puse la decisión en Dios, confiando en Él, e hice mi petición. Ningún extranjero puede ir a la tierra de la India [Occidental] si no tiene una orden del rey. En aquella época, el nuncio, que es el enviado del papa en Madrid, era el bendito cardenal Marescotti, ${ }^{44}$ quien me ayudó con sus consejos.

Finalmente obtuve la orden de la reina y la merced otorgada causó gran contento entre algunos de mis amigos. El noble en cuya casa me alojaba preparó todo lo preciso para el viaje y me entregó cartas de recomendación para algunos amigos suyos. La cédula real ordenaba al ministro, a los obispos, arzobispos y gobernantes de todas las regiones de las Indias que me diesen ayuda [...] salí de Madrid para dirigirme a la ciudad de Cádiz, que es un puerto situado sobre el Océano Atlántico [Bahr alMuhit]. Después de viajar doce días por tierra llegué a ella y vi las naves de la India [Occidental] listas y prestas para zarpar. En este puerto está establecida la oficina encargada de los asuntos reales, donde entregué la orden de la reina para registrarla y me entregaron una segunda orden en respuesta.

\section{E1 viaje a Nueva España y regreso a España}

\section{Inicio del viaje ${ }^{45}$}

El día doce del mes de febrero del año de Cristo de 1675 presenté mi cédula real con las cartas al general [almirante] de los galeones don Nicolás [Fernández] de Córdoba, que me apreció y me recibió con gran generosidad, dándome, como se orde-

Occidentales”, que utilizaron los cronistas y geógrafos españoles a partir de la llegada de Cristóbal Colón a esas tierras en 1492: "las cuales las llamaron Occidentales, á semejanza de las Orientales que tomaron este nombre del río Indo, que está en ellas...” (López de Velasco, 1894, p. 6). Entre los historiadores árabes, la expresión al-Hind al-Garbiyya (India Occidental) fue usada en el siglo xvi por el historiador marroquí Abū Fāris 'Abdal al-Fištālī, mientras que en el siglo xvII el escritor morisco Ahmad bin Qāsim empleó la expresión al-Hunūd al-Magribiyya (Indias Occidentales) (Matar, 1999, p. 186). Para la presencia de la expresión en turco a finales del siglo XVII en la obra otomana Taribi-i Hind-i Garbi, véase nota 48.

${ }^{44}$ Galeazzo Marescotti (1627-1726), cardenal italiano, nuncio apostólico en España entre 1670 y 1675 , en la corte de Carlos II en Madrid.

${ }^{45}$ Al-Ŷarrāḥ (ed.), 2001, p. 46; Rabbāt (ed.), 1906, p. 12. 
naba, un camarote en su barco. Introduje mis pertenencias en el camarote y cerré la puerta. Este galeón era el principal del resto de los galeones.

Había llevado conmigo de Cádiz a un diácono de confesión griega [min tä'ifa al-rūm] nacido en Atenas, ${ }^{46}$ porque no encontré a nadie de mi comunidad religiosa [millatī] ni de mi país. Llegué a tener un gran arrepentimiento a causa de que había enviado de regreso a mi sobrino, el diácono Yūnān, a la tierra de Oriente [bilād al-Šarq]. Sin embargo, no es útil el lamento. Algunos compañeros me habían aconsejado: "Este griego [al-rūmī], cuando llegues a la tierra de la India [Occidental], se te rebelará y se alejará de ti”. Cuando llegué a allí, sucedió lo que me habían dicho.

Por tanto, ese día mencionado, levantamos las anclas, elevamos las velas y zarpamos. El número de la flota era de diez y seis galeones, que fueron despedidos desde el puerto con detonación de cañones, tañido de trompetas e izamiento de banderas $\mathrm{y}$ banderines.

\section{En la flota del rey ${ }^{47}$}

Algunos de los pasajeros estaban felices y otros estaban tristes por tener que dejar a sus familias. Cada tres años esta flota zarpa una sola vez hacia un país de las Indias llamado Perú, a mil quinientas leguas de distancia al interior de la tierra del Nuevo Mundo [Yeni Dünya, México], ${ }^{48}$ de donde se trae el tesoro del rey y también los mercaderes cargan los galeones con todo género de bienes que venden en esta tierra. No permiten que ningún hombre que no sea español los acompañe si no tiene una

${ }^{46}$ La petición que hizo don Elías (con la estampa de su firma), fechada en Cádiz el 3 de febrero de 1675, estaba relacionada precisamente con que se le permitiera llevar a una persona que le ayudara a celebrar la misa caldea en tierras americanas (AGI, Contratación, leg. 5440, N. 2, R. 135).

${ }^{47}$ Al-Ŷarrāh (ed.), 2001, p. 47; Rabbāt (ed.), 1906, pp. 12-13.

${ }^{48}$ La expresión turca Yeni Dünya (Nuevo Mundo, en árabe, al-'Ālam al-Ŷadīd o al-Dunyā al-Ŷadīda) se remonta al siglo Xvi, cuando un escritor turco anónimo escribió, entre 1583 y 1584, la obra otomana más antigua sobre el nuevo mundo, titulada Taribi-i Hind-i Garbi (Historia de la India del Occidente, manuscrito número 4969, Beyazid Library de Estambul), (Goodrich, 1987, pp. 317-319; Goodrich, 1990; Lunde, 1992a, pp. 26-33; Gruzinski, 2015, pp. 18-19). 
licencia del rey, como lo he mencionado anteriormente. Éstas son, hasta ahora, las leyes y los decretos establecidos en los tiempos de Carlos V, rey de España y Hungría, en cuya época se conquistaron las Indias. Los galeones regresan con riquezas de oro y plata por un valor de veinte o veinticinco millones...

\section{El país del nuevo mundo ${ }^{49}$}

Mi amigo, el virrey depuesto, ${ }^{50}$ me aconsejó ir a Nueva España [Yeni Dünya] porque estaba apenado a causa de no haber podido hacer nada de lo que me prometió y estaba dispuesto a dotarme de todo lo necesario y me dio cartas de recomendación para el virrey de Nueva España, ${ }^{51}$ quien era cercano a él. Con la ayuda de Dios, exaltado sea, y su buen y gran socorro, empezamos a registrar las noticias [ajbār] de nuestro viaje hacia el país del Nuevo Mundo, México [Yeni Dünya, alMaksik]. En el mes de diciembre del año 1681, nos embarcamos en la gran nave llamada Capitana [Qabiṭānā].

\section{Llegada a Puebla ${ }^{52}$}

Después de 15 días dejé esta ciudad [Oaxaca, Wājākāā] en dirección a la Ciudad de México [Mījìikū], donde reside el virrey [wazir al-malik, ministro del rey] [...]

Luego llegamos a la villa de Tepeaca [Tibyākā] [...] y más tarde a la ciudad de Puebla de los Ángeles [madiña Būbūlā dih lūs Anjilīus], es decir, la ciudad del Pueblo de los Ángeles [Madīna Šacb al-Malā'ika]. Entré a la ciudad y me establecí con uno de mis amigos.

La ciudad del Pueblo de los Ángeles tiene grandes palacios y monumentos, ricas iglesias, como la Catedral, con decoración

49 Al-Ŷarrāh (ed.), 2001, pp. 98 y 101; Rabbāt (ed.), 1906, p. 57.

${ }^{50}$ Baltasar de la Cueva, conde de Castellón y marqués de Malagón, virrey de Perú (1674-1678).

${ }^{51}$ Tomás Antonio de la Cerda y Aragón, conde de Paredes y marqués de la Laguna, virrey de Nueva España (1680-1686).

${ }^{52}$ El subtitulado es agregado mío. Al-Ŷarrāḥ (ed.), 2001, p. 109; Rabbāt (ed.), 1906, pp. 63-64. 
muy ornada, con abundante uso de plata y oro en su decoración. En esta ciudad reside el obispo don Emmanuel de Santa Cruz ${ }^{53}$ hombre educado, temeroso de Dios, que dispone de un ingreso de 80000 piastras anuales. También en esta ciudad hay conventos de todas las órdenes monásticas [tawä'if al-rabbān].

\section{Descripción de México [Maksikū $]^{54}$}

Después de dos días salí en dirección a la Ciudad de México [balad Mìjīkū], que está a una distancia de veinticuatro leguas [farsa] de esa ciudad [Puebla]. Llegué y entré a la Ciudad de México ${ }^{55}$ y me hospedé con uno de mis amigos [așhābi]. Traía conmigo una carta para él de la ciudad de Guatemala; me recibió con honor y generosidad. Un día después caí enfermo y permanecí diez días en cama. También traía yo una carta para el virrey [wazír] de esta tierra de parte de su pariente, mi amigo el virrey que estaba en el Perú [al-Bīrūh]. El virrey me enviaba continuamente a sus médicos [hukāmahi] para que me asistieran. Diez días después sané, con la ayuda y la protección

${ }^{53}$ Manuel Fernández de Santa Cruz (Palencia, España, 18 de enero de 1637-Puebla, México, 1 de febrero de 1699), obispo de Guadalajara y de Puebla, promovió obras religiosas importantes especialmente en esta última ciudad (Galí, 2001, pp. 7190). Destaca también el vínculo intelectual y religioso que Fernández de Santa Cruz mantuvo con sor Juana Inés de la Cruz (Paz, 2004, pp. 182-183).

${ }^{54}$ Al-Ŷarrāh (ed.), 2001, pp. 109-110; Rabbāt (ed.), 1906, p. 64.

${ }^{55}$ El famoso cronista del siglo XVII Antonio de Robles registró en su Diario de sucesos notables la entrada en la Ciudad de México del "canónigo de Babilonia”: [miércoles 8 de julio de 1682] “Canónigo de Babilonia.- Estos días entró en México un canónigo de Babilonia, que viene del Perú, D. Elías de San Juan, vestido con sotana de seda y con cuello blanco, con turca sobre ropa. Viene a pedir limosna para aquella catedral, con bula de Clemente X [sic] y cédula real” (Robles, 1972, pp. 21-22). Al referirse a esta cita del Diario de Robles, se ha hecho una versión errónea de la palabra "turca", que presenta una imagen exótica de la vestimenta del canónigo don Elías. Por ejemplo, Paul Lunde (1992b, p. 64) escribió: "La presencia de Elías en la Ciudad de México el 8 de julio de 1682 causó sensación: un diarista contemporáneo dice que estaba vestido con una sotana de seda o balandrán, con un cuello blanco y llevaba un turbante en su cabeza, como un turco". También en relación con el mismo Diario, John-Paul Ghobrial (2014, p. 52) indicó que Elías "estaba vestido como un turco": "un cronista español escribió en su diario que él estaba vestido como un 'turco', con una sotana grande negra y el cuello blanco de un sacerdote". El texto de Robles no dice que llevara un turbante sobre su cabeza ni que fuera vestido como turco, sino que llevaba una "turca" sobre su ropa, es decir una especie de "cubierta", sobre su vestido, que usaban los eclesiásticos en el siglo XVII (Maza, 1963, p. 55). Las cursivas son mías. 
de Dios. Me dirigí entonces a visitar al virrey y a su esposa, los dos me recibieron con amor y rostros afables. El virrey me ofreció que me hospedara con él en el palacio, su bondad me sobrecogió y le agradecí su amabilidad por eso. No quise hospedarme con él, sino que alquilé una casa en trescientas sesenta piastras por un año. También me compré un carruaje y mulas en seiscientas cincuenta piastras. Después empecé a ir a visitar a los nobles [al-ašrāaf]. Primero visité al obispo [al-mutrān] de la ciudad, luego a los otros notables [al-a'ayān]. El obispo me otorgó un permiso [dustūr] para celebrar misa en cualquier lugar que yo deseara. Cada noche, al caer la tarde, me dirigía a conversar con el virrey [wazīr] durante dos horas y luego regresaba a mi casa.

En cuanto a este lugar, está situado en un valle [tierra hundida], y al lado de esta ciudad hay una laguna [buḅayra] de agua que brota de la tierra. Hace algunos años llovió tanto que la ciudad se inundó y muchas casas se llenaron de agua y se cayeron. Esta tierra no tiene una base sólida.

Qué diremos de las iglesias que están en esta ciudad y sobre la nobleza y la belleza de sus construcciones y la abundancia de su riqueza, es algo que no puede describirse. En esta ciudad hay tres conventos de los monjes de San Francisco [Mār Afaransīs], dos conventos de los monjes de Santo Domingo [Mār 'Abd al-Ahad], dos conventos de los monjes jesuitas, tres conventos de los monjes de San Agustín [Mār Agustịnūs], dos conventos de los monjes de la Merced [al-Marsī], hospitales [māristānāt] para la curación de los enfermos, diecisiete conventos de monjas religiosas y un convento de los monjes carmelitas, así como la catedral [al-kanisa l-kabira] y otras numerosas iglesias.

\section{La iglesia de la virgen de Guadalupe y la bistoria de Juan Diego ${ }^{56}$}

A media legua fuera de la ciudad hay una capilla [kanisa] dedicada a la Virgen María, llamada Guadalupe [Wādālūbī]. Nos

${ }^{56}$ Al-Ŷarrāh (ed.), 2001, p. 110; Rabbāt (ed.), 1906, p. 65. En la Ciudad de México, don Elías visitó la iglesia de la Virgen de Guadalupe y relató la historia de la aparición de la Virgen al indio Juan Diego; sin duda, éste es el primer relato escrito en árabe 
contaron que pocos días después de la llegada de los españoles [al-sabanyuliyya] a esta tierra, uno de los indios [bunūd], llamado Juan Diego, rondaba fuera de la ciudad cuando una majestuosa mujer de extrema belleza se le apareció y le dijo: "Ve con el obispo de la ciudad y dile que construya para mí una casa en este lugar". El mencionado indio [al-hindi] estaba temeroso por la luz brillante del rostro de la mujer y se marchó rápidamente, como le había indicado la señora, y le dijo al obispo todo lo que le ordenó a él. Cuando el obispo observó a este indio, en su triste estado, con su ropa miserable, le ordenó que se alejara. Este pobre hombre, abatido y humillado, regresó al lugar en el que la majestuosa mujer había hablado con él. Una segunda vez se le apareció en el lugar referido y le repitió lo que le había dicho la primera vez, que regresara con el obispo y le dijera lo que le había ordenado. Obedeció y fue por segunda vez con el obispo y le expuso todo lo que esta señora le había ordenado. El obispo, otra vez, lo despreció y le ordenó que fuera humilde y se alejara. Triste y rechazado regresó al mismo lugar y la señora se le apareció por tercera vez, y le dijo: “¿Por qué no has hecho lo que te ordené?”. Entonces él le contestó así: "Mi señora, hice lo que me indicaste y fui dos veces con el obispo y le expuse todo lo que ordenaste, pero me despreció y no me creyó". La señora le dijo: "Ve por tercera vez con el obispo y dile todo lo que te he ordenado. Toma estas rosas y entrégaselas al obispo para que crea en lo que le dices”.

Le entregó las rosas, que estaban fuera de temporada. El indio cogió las rosas y las puso en el sayal [al-rid̄à] que llevaba puesto. Se dirigió a la casa del obispo, y cuando los sirvientes lo vieron y lo reconocieron fue rechazado y expulsado, pero él les dijo: "Por Dios, déjenme hablar con el obispo, porque tengo un regalo de parte de la Señora Española para él”. Los sirvientes le informaron al obispo sobre esto y entonces el obispo les ordenó que lo dejaran entrar. Cuando el indio estuvo frente a él, le dijo: “¡Oh, mi señor! La señora me ha enviado

que describe ese acontecimiento religioso en la Nueva España. Véase, para el relato histórico de la aparición de la Virgen, la obra publicada originalmente en 1666, que posiblemente consultó don Elías, del bachiller Luis Rivera Tanco (1883) (Brading, 2015, pp. 133-147). 
tres veces con usted para decirle que le construya una casa en ese lugar, así que le envió a usted estas rosas para que dé crédito a mis palabras y que tenga la certeza de que ella me ha enviado a usted". Cuando el indio soltó las rosas de su sayal, el obispo vio con sorpresa esto, porque no era temporada de rosas. Aumentó su sorpresa al ver que la imagen de la Virgen María estaba impresa en el sayal del indio, que era de rosas todo tejido. En ese momento, el obispo cayó de rodillas frente al indio y le pidió perdón. Rápidamente le recogieron al indio las rosas en el momento en que se imprimió la imagen de la Virgen en su sayal. Después, el obispo llevó el mencionado sayal en procesión, con el repique de campanas, y lo colocó en el altar mayor, con gran alegría y fiesta. Luego salieron hacia el lugar indicado y el obispo ordenó la edificación de la capilla en el lugar en que la Virgen se le había aparecido al indio, la cual se llama Capilla de la Virgen María de Guadalupe. El indio Juan Diego pasó su vida al servicio de la Virgen en esta capilla y falleció como los piadosos.

Como hemos mencionado, esta capilla está fuera de la Ciudad de México, a media legua, es muy rica en plata y oro, así como en ornatos valiosos. Las nueve gradas de la escalinata del altar mayor están hechas de plata. Los pilares del altar también son de plata. Construyeron una especie de puente de dos codos de altura para pasar del límite de la capilla al interior de la ciudad, debido a que esta tierra en épocas del estío, cuando llueve se convierte toda ella en una laguna y sólo pueden caminar por esa pasarela, pues en esta ciudad empiezan las lluvias desde el principio del mes de mayo [ayār] hasta finales del mes de septiembre [aylül], a diferencia de lo acostumbrado y ocurrido en nuestro país.

\section{El ataque de los herejes al puerto de Veracruz ${ }^{57}$}

Permanecí descansando en esta ciudad alrededor de seis meses hasta que llegó un navío de España, que traía un número de cartas de los comerciantes para sus socios. 
En este navío llegó un hombre estafador que pretendía haber sido enviado por el rey para investigar sobre los transgresores y hacer un registro del tesoro del rey. Este indagador causó terror en el corazón de muchos transgresores. Cuando el virrey escuchó sobre esto, escribió al gobernador del puerto para que viera las órdenes que traía consigo ese hombre, pero éste no quiso mostrarlas. Entonces el virrey supo que se trataba de un mentiroso impostor y envió soldados tras él para buscarlo y encontrarlo. El virrey ordenó su procesamiento. ${ }^{58}$

En esos días llegaron algunos barcos piratas [corsarios, qurșann] al puerto de Veracruz [Wirākrūs], todos ellos eran herejes [harātiqa] reunidos de todos los géneros de sectas [confesiones religiosas, al-tawä iff. Llegaron en la noche y se adentraron a tierra una legua lejos del puerto y entraron a la ciudad como ladrones, porque el puerto no tenía muros. Se dirigieron a la casa del gobernador del puerto y lo tomaron cautivo. Después de esto, entraron y sacaron a la gente, hombres y mujeres, para retenerlos en la iglesia mayor, los encerraron y pusieron guardias en las puertas. Los corsarios empezaron a saquear y robar los monasterios, las iglesias y las casas durante tres días. Después, sacaron a la gente de la iglesia e hicieron que llevaran el botín del saqueo hasta donde estaban los barcos anclados y los llevaron lejos, hacia una media legua. Llevaron el dinero y a todos los hombres y esclavos a los barcos, y los condujeron a una isla cercana a una legua del puerto. Los desembarcaron allí y les dijeron: "O liberamos sus almas o los matamos a todos". Exigieron ciento cincuenta mil pesos. Estos malhechores enviaron, por su parte, a pedir el rescate de ellos a la mencionada ciudad de Puebla. Después de diez días les entregaron ciento cincuenta mil pesos y liberaron a la gente española y se llevaron a los esclavos negros y todo el dinero del saqueo de la ciudad, que ascendía a ocho millones. El número de esos corsarios poderosos era de seiscientos individuos y el de los españoles con sus esclavos era de más de cuatro mil. El jefe de los corsarios era

${ }^{58}$ Se trata de Antonio de Benavides, el Tapado, que llegó a Nueva España en mayo de 1683 haciéndose pasar por visitador real y con títulos de nobleza; fue procesado y ahorcado el 12 de julio de 1684 (Robles, 1972, pp. $42-48$ y 72). Se especuló entonces sobre la identidad de este personaje, si era un espía o un impostor (Rubio Mañé, 2005, vol. 1, p. 88). 
un hereje que tenía un compañero y un socio español llamado Lorencillo[Nasīlyū]. Tuvieron una disputa sobre el reparto del dinero entre los dos. Lorencillo mató al jefe hereje y tomó su lugar como líder de los corsarios. ${ }^{59}$

Yo había traído a esta villa un cargamento de cochinilla [qirmiz] que compré en Oaxaca por mil pesos, pero me lo robaron junto con otros bienes.

Mientras los piratas estaban en esta isla, llegaron barcos de España y, al entrar al puerto de Veracruz, el virrey informó al general la situación real para que luchara y destruyera a los piratas antes de que llegaran. El general izó la bandera para reunir alrededor de él a los capitanes de todos los barcos y hacer un consejo [diwān] y compartir la responsabilidad entre ellos, pues el general no quería ser el único culpable porque los barcos estaban cargados con mercaderías. Temía que le hundieran un barco o lo incendiaran en la batalla. Cuando el general se alejó del puerto se reunieron y celebraron su consejo, Lorencillo los observó, levanto sus velas y zarpó. Se burló de los barcos españoles y salió frente a ellos sin temor, después de que se había llevado consigo a más de dos mil cautivos, esclavos negros e indios, esto sucedió en el año cristiano de 1683.

\section{De México a Bagdad por la vía de China ${ }^{60}$}

Cien años antes de esta fecha, en tiempos de Felipe IV, rey de España, zarparon barcos de Nueva España [Yeni Dünya] rumbo a los confines de China. Avistaron una isla, se apode-

${ }^{59}$ En mayo de 1683, Veracruz fue tomada por sorpresa, casi sin resistencia, por filibusteros mandados por el francés Michel Grammont y por el famoso pirata holandés Lorencillo (Laurent de Graff). La ocupación y el saqueo de la ciudad duró dos semanas, del 7 al 30 de mayo. Los piratas se retiraron cuando el virrey de Nueva España pagó los 150000 pesos que exigían como rescate de unos rehenes. Se llevaron también a 1300 esclavos. Don Elías describió el saqueo de Veracruz como testigo presencial (Robles, 1972, pp. 42-47; Rubio Mañé, 2005, vol. 2, pp. 118-124).

${ }^{60}$ El subtítulo corresponde a la edición de 1906. Al-Ŷarrāh (ed.), 2001, pp. 113115; Rabbāt (ed.), 1906, pp. 67-69. Don Elías intentó navegar y regresar a Bagdad por la vía del Pacífico, saliendo de Acapulco rumbo a Filipinas para tomar un barco armenio desde Manila hasta Surat (India) y de ahí viajar a Bagdad. Por un desacuerdo monetario con el nuevo designado para gobernar las Filipinas, según él, se malogró su intención de darle la vuelta al mundo. 
raron de ella y le pusieron por nombre Filipinas [Fīlībīnās], en honor del mencionado rey. Los españoles se establecieron allí. Años después, llegaron a esta isla barcos con varios sacerdotes y frailes para instruir a su población a fin de convertirlos del paganismo a la fe de Cristo.

Cada año llegan barcos de estas islas a la Nueva España, cargados con mercaderías de China. Los barcos tardan en llegar, de la isla a la Nueva España, ocho meses; sin embargo, el viaje de regreso es de tres meses.

Asimismo, cada año sale un barco a esta isla de la ciudad de Surat, destinado a los comerciantes armenios, llamados $\hat{y} u l f i e s,{ }^{61}$ que residen en esa isla. Éstos son los armenios que recogen el dinero del barco y lo prestan a crédito a los españoles por el plazo de un año. Al cumplirse el año llega otro barco de Surat y recogen de los españoles el dinero del año anterior y vuelve a darles a los españoles por el mismo plazo un nuevo préstamo. ${ }^{62}$ No se otorga permiso a otras comunidades [tawä'if], pues no llegan a esta isla sino sólo barcos de los armenios de Yulfa con rumbo a Surat y de esta villa a mi país. ${ }^{63}$ Sin embargo, me abstuve de esto por un incidente con el hombre que estaba por partir para gobernar esa isla, ${ }^{64}$ pues me había pedido que le prestara diez mil pesos. Consulté al virrey y me dijo: "Ten cuidado, porque está endrogado, le han dado un préstamo de dos mil pesos"; entonces me abstuve de este viaje y decidí regresar a España.

${ }^{61}$ Se refiere a los armenios establecidos en la ciudad de Nueva Ŷulfa, importante ciudad que fue fundada en Isfahán, Irán, en 1605, por orden del shab 'Abbās (Gregorian, 1974, pp. 652-680). Don Elías mostró su conocimiento del papel desempeñado por los armenios habitantes de esa ciudad en el comercio internacional de entonces.

${ }^{62}$ Los $\hat{y} u l f i ́ e s$ desarrollaron el crédito y el sistema de comanda durante los siglos XVII y XVIII en sus transacciones comerciales (Aslanian, 2007, pp. 124-171).

${ }^{63}$ Los armenios crearon una red de comercio marítimo desde el Mediterráneo, que pasaba por Nueva Ŷulfa y llegaba hasta el Océano Índico y Manila (Sarkisian, 1987, pp. 1-33; Aslanian, 2011). El importante puerto comercial de Surat, en Gujarat (costa noroccidental de India), atrajo a los mercaderes armenios desde el siglo XVI, pero su actividad en Surat se fortaleció con la fundación de Nueva Ŷulfa: "De Isfahán ellos llegaron a Basora sobre el Éufrates y desde ahí navegaron a India. El primer puerto en donde formaron un asentamiento permanente en India fue la ciudad de Surat" (Seth, 1897, pp. 27-28; Gokhale, 1979, pp. 38-39).

${ }^{64}$ El 30 de abril de 1683 se dio noticia en Nueva España del nombramiento de Gabriel Cruzalaegui como gobernador de Filipinas (1684-1689) (Robles, 1972, p. 40). 


\section{Viaje a Cuba ${ }^{65}$}

Hablemos, ahora, de nuestro regreso. Cuando los barcos estaban listos para regresar a España, salí de la Ciudad de México hacia el puerto de Veracruz, a ochenta leguas. Hablé con el capitán de los barcos para que me llevara a España y él me pidió mil pesos de pasaje, que incluía comida y bebida. La regulación de estos barcos especifica la renta de un cuarto de dos codos, y la extensión de un codo y un tercio y un codo y medio. Encontré que la demanda de mil pesos era difícil de cubrir para mí, sin embargo, a pesar de esto acepté. Después de ocho días, los capitanes de los barcos se reunieron para celebrar un concejo y una consulta para ver si les era posible salir de las Indias y llegar a España en esos meses, pero dejaron la votación porque no podían viajar sino después de tres meses. Habilitaron entonces un barco pequeño, con la correspondencia y las noticias de este país, y lo enviaron antes que ello a España. Cuando yo vi eso, arreglé mis cosas, porque este puerto es muy caluroso, su agua insalubre y su aire peor, así que me organicé y abordé este pequeño barco que enviaron a España, dirigiéndome con él rumbo a la isla llamada La Habana [Lāwānā], ${ }^{66}$ que es el puerto para los galeones [galāyin] del Perú y para los barcos del Nuevo Mundo, a los que llaman flota [al-falütā].

En el puerto de Veracruz encontré a un amigo que me sugirió comprar dos cargas de cebolla seca y dos cajas de manzanas para dar como regalos, hice las compras y cumplí su consejo...

Con el poder de Dios hicimos la travesía y luego de veinte días llegamos a la isla mencionada de La Habana, estábamos felices y complacidos.

El gobernador de la isla era el hermano del general que me había llevado al Perú, a quien le ofrecí como regalo las cebollas

${ }^{65}$ Al-Ŷarrāh (ed.), 2001, p. 121-122; Rabbāt (ed.), 1906, pp. 71-72.

${ }^{66}$ El Diario de sucesos notables registra que don Elías había salido del puerto de Veracruz, vía La Habana, para dirigirse a España: "[Sábado 25 de noviembre de 1684] Ida del aviso.- Vino nueva cómo salió el aviso primero de la Veracruz para España a 18 de este: fueron en él el abad interino de San Antón D. Diego de Rivera, el canónigo de Babilonia y el Dr. de Santo Domingo" (Robles, 1972, p. 76). Esta información coincide plenamente con lo relatado por don Elías, al indicar que él había tomado el pequeño barco que salió de Veracruz a La Habana y que llevaba las noticias y la mensajería para España. 
y las manzanas. Se sorprendió y me preguntó: “¿Cómo supiste que nosotros necesitamos cebollas y manzanas en esta isla?”. Cuando siembran cebolla en la isla crece del tamaño de la cola de un ratón. Si la dejan para que crezca, se marchita y se seca.

Permanecí en la isla cuatro meses y medio hasta que llegaron los barcos del Nuevo Mundo [México]. La isla tiene un buen clima, su agua es buena y su gente es amigable.

Cuando me disponía a salir de esta isla para dirigirme a España, me llegaron, en retribución de las cebollas y las manzanas, nueve cajas de azúcar y jarras con conserva. Había ya adquirido un pasaje por trescientos cincuenta pesos en el barco que llegó de Caracas [Karākis], así que nos dispusimos a partir.

Con la ayuda de Dios llegamos a la isla de Lucaya [Bahamas], pero cayó sobre nosotros una turbulencia, a causa de la gran intensidad de los vientos, que duró once días. Los barcos se dispersaron sobre la faz del mar. Nosotros permanecimos en llanto y lamentaciones, con oraciones y procesiones en los barcos, haciendo votos a las iglesias y santos.

Después de los once días mencionados, Dios nos ayudó y se calmaron los rugidos del mar; nuestros barcos que habían sido dispersados se reunieron otra vez. Durante la noche encendían las linternas para que no se alejaran y se perdieran, también para que no se acercara mucho un barco a otro y chocaran entre ellos y se destruyeran.

Entonces llegó a nosotros un viento favorable y retomamos nuestro rumbo, dirigiéndonos a Cádiz. Doce días después descubrimos la tierra, al amanecer. El viento no ayudó mucho hasta el mediodía.

\section{En el puerto de Cádiz ${ }^{67}$}

Entramos, a salvo, al puerto de Cádiz. Barcos de guerra del rey de Francia estaban anclados en las afueras del puerto. También había barcos del rey de España anclados frente a ellos.

Cuando pasamos entre esos barcos, los saludamos con el batir de cañones. Los barcos franceses y españoles respondieron 
nuestro saludo también con el batir de cañones, a ambos lados, lo que continuó hasta que el humo se convirtió en una niebla. Entramos al puerto y anclamos. Al día siguiente, unos amigos de la ciudad llegaron a nosotros en un bote y nos llevaron a tierra. Por orden del jefe del Concejo [al-diwān], que se llama presidente [barasidintib], sacamos nuestros cajones sin que fueran abiertos y revisados, como es costumbre.

Diez días después me dirigí a la ciudad de Sevilla para recoger dos mil pesos que había prestado al capitán del barco a fin de que comprara lo necesario para éste. Pero cuando el capitán llegó a Cádiz, detuvieron el barco y lo confiscaron porque le debía a la Iglesia de Sevilla treinta mil pesos. Entonces partí e hice una reclamación; el presidente decidió, con justicia, y estipuló que: “Antes que todo, se pagarán esos dos mil pesos, porque sin ese préstamo no tendríamos al barco de regreso con nosotros".

Me dieron el pago y fui a Cádiz y adquirí un pasaje en un barco holandés que se dirigía a Roma. Tenía conmigo a dos sirvientes armenios [min awlàd al-arman $].^{68} \mathrm{Había}$ traído de las Indias [Occidentales] cuatro aves que se llaman en lengua franca papagayos [babag $\bar{a}$ ] y que hablan como los humanos [al-insān ]. ${ }^{69}$ También traje un candelabro [qandīl] de plata, con un trabajo extraordinario y con un valor de mil cuatrocientas cincuenta piastras. Los ofrecí en regalo a nuestro señor el papa y a la Iglesia de la Propaganda de la Fe. Cuando los cardenales lo vieron, se alegraron mucho por la delicadeza de su obra. En ese entonces, nuestro señor el papa Inocencio XI, poseedor de correcta memoria, me otorgó nombramientos de los que no soy merecedor. ${ }^{70}$

Alabanza a Dios, por siempre, Amén.

${ }^{68}$ Al final del viaje aparece nuevamente la relación de don Elías con los armenios, ahora en Europa (véase Aslanian, 2008, pp. 127-188).

${ }^{69}$ En el relato de viaje de imām al-Bagdādī a Brasil en el siglo XIx hay una referencia a la particularidad de los papagayos de hablar como humanos (Marín Guzmán, 2011, pp. 162-163).

${ }_{70}$ Don Elías recibió cinco nombramientos: i) archidiácono de la Iglesia de Bagdad; ii) protonotario apostólico; iii) portador de la Cruz de San Pedro; iv) conde palatino, y v) capellán de la Iglesia del rey de España (Horae diurnae et nocturnae ad usum Orientalium, 1692, en Schnurrer, 1811, pp. 258, 260). 


\section{Conclusiones}

Los manuscritos de Elías de Babilonia, en los que se incluye su relato de viaje, son sin duda en muchos aspectos de sumo interés, pues como mencioné al inicio de este trabajo, no sólo contienen el primer relato en árabe, hasta ahora conocido, sobre la América hispana, sino también la primera historia escrita en esa lengua sobre el Nuevo Mundo.

No obstante que los manuscritos fueron descubiertos por el sacerdote jesuita Antoine Rabbath a principios del siglo XIX en Siria, quien editó y publicó en Beirut únicamente el relato de viaje en 1905 y 1906, sólo después de la segunda mitad del siglo pasado aparecieron las primeras traducciones de la ribla en lenguas europeas, inglés, italiano, holandés (parcial) y francés, pero hasta la fecha no se ha publicado en español una versión completa de ese importante viaje.

Por otra parte, el conocimiento sobre el autor de esos textos había sido muy limitado, lo que hacía difícil comprender y valorar la obra en su conjunto con todas sus particularidades y complejidades. En efecto, uno de nuestros objetivos al realizar este estudio fue dilucidar elementos biográficos de nuestro personaje que pudiesen aclarar algunos supuestos y errores que han llevado incluso a algunos estudiosos contemporáneos a modificar las fechas del viaje de don Elías, sin ningún fundamento (por ejemplo, Marín Guzmán, 2009, pp. 11, 21-22, $71,92)$, por lo que considero necesario incluir una cronología basada y apoyada en fuentes documentales.

Al profundizar en esos aspectos biográficos, personales y familiares, se va configurando un personaje que adquiere no sólo una dimensión especial en la historia regional de su comunidad (católica medio oriental, en general, y caldea iraquí, en particular), sino también en el desarrollo de los vínculos y las relaciones de esa comunidad con los intereses religiosos, económicos y políticos de algunos poderes europeos del siglo XVII, el Vaticano y Francia, en Medio Oriente.

En este sentido, la historia familiar y la vida del sacerdote Ilyās ibn al-qissīs Hannā l-Mawșilī (Elías hijo del sacerdote Juan de Mosul) ofrecen elementos que ayudan a configurar una dimensión más completa de nuestro personaje - considerando 
sus variadas facetas- y, por lo tanto, a tener una mejor comprensión de algunos aspectos no del todo claros que aparecen en la narración de su viaje.

Importa destacar en primer lugar el aspecto religioso, puesto que don Elías y su familia formaban parte de ese grupo de familias árabes conversas al catolicismo, cristianos caldeos, que decidieron vincularse a la Iglesia de Roma y a sus intereses misionales en Medio Oriente, a través del Colegio de la Propaganda de la Fe en 1622. Los viajes a Roma fueron un elemento fundamental en la formación doctrinal y el fortalecimiento de los intereses políticos y económicos de la comunidad caldea con el Vaticano. La autorización para el acopio de limosnas y la formación de jóvenes de las iglesias locales en Roma formaron parte de esta estrategia misional.

En segundo lugar, los vínculos de la comunidad caldea y sus dirigentes no sólo eran de carácter religioso y misional, sino que, al relacionarse de manera particular con el cónsul francés en Alepo, los intereses religiosos también tenían una motivación económica y política, pues el cónsul Picquet fue un actor decisivo para vincular directamente los intereses económicos y políticos de Francia en el Imperio otomano con la causa misional católica. Precisamente en París, don Elías realizó una actividad importante: no sólo fue recibido por el rey Luis XIV y visitó al duque de Orleans y al duque de Saint-Aignan, sino que su permanencia de ocho meses en París coincidió con la llegada a esta ciudad de Solimán Aga, a quien sirvió como intérprete en su misión como enviado otomano ante el rey de Francia.

En tercer lugar, el viaje a España resultó, sin duda, un momento decisivo en la consecución de los varios intereses del canónigo de Babilonia, pues le dio la oportunidad de conocer el Nuevo Mundo y de ampliar sus vínculos hacia horizontes nuevos. En este aspecto adquiere relevancia la preocupación y el interés constante en registrar la riqueza material de las tierras que visitó en América, así como el objetivo de vincularse con dignatarios civiles y eclesiásticos que le permitieron tener acceso a cierto bienestar y acopio de bienes durante su periplo por tierras americanas. Por otra parte, es importante destacar el papel desempeñado por los hijos de los hermanos 
de don Elías de San Juan, que, precisamente con el apellido De San Juan, crearon una dinastía en la formación del arabismo en España y en la conservación de manuscritos árabes en la Biblioteca Real de Madrid.

Dirección institucional del autor:

Facultad de Filosofía Samuel Ramos

Universidad Michoacana de San Nicolás de Hidalgo

Francisco J. Mújica s/n, colonia Felícitas del Río

Ciudad Universitaria, Edificio C-4

58030 Morelia, Michoacán, México

\section{Referencias}

Aвoona, H. (2008). Assyrians, Kurds, and Ottomans: Intercommunal relations on the periphery of the Ottoman Empire. Amherst, NY: Cambria Press.

Alishan, L. M. (1899). Sissouan ou L'Armeno-Cilicie: description géographique et historique. Venecia: S. Lazare.

AL-JARRÂH, N. (Ed.) (2011). Elias al-Marwsilî, un Irakien en Amérique au XVII siècle, récit de voyage. (Trad. Jean-Jacques Schmidt). París: Actes Sud.

Al-ŶYARRĀH, N. (Ed.) (2001). Al-Dabab wa l-ạsisifa. Riḥla Ilyās alMarusili ilà Amìrkā. Awrwal riḅla šarqiyya ilà l-ālam al-ŷadìd [E] oro y la tormenta. El viaje de İlyās al-Mawșilī a América. El primer viaje oriental al Nuevo Mundo]. Abu Dabi-Beirut: Dār alSuwīìi li l-našr wa l-tawzī‘ y al-Mu’assasa al-'arabiyya li-dirāaāt wa l-našr.

Armiño, M. (2015). "Prólogo". En Molière, El misántropo / El burgués gentilhombre (pp. 9-72). Madrid: Alianza.

Aslanian, S. (2007). The circulation of men and credit: The role of the Commenda and the family firm in Julfan society. Journal of the Economic and Social History of the Orient, 50(2-3), 124-171.

Aslanian, S. (junio de 2008). "The salt in a merchant's letter": The culture of Julfan correspondence in the Indian Ocean and the Mediterranean. Journal of World History, 19(2), 127-188. http:// www.dx.doi.org/10.1353/jwh.0.0014

Aslanian, S. (2011). From the Indian Ocean to the Mediterranean: The global trade networks of Armenian merchants from New Julfa. Berkeley, CA: University of California Press. 
Boullaye, F. de la. (1657). Les voyages. París: François Clouisier.

Brading, D. A. (2015). La Nueva España. Patria y religión. México: Fondo de Cultura Económica.

Budge, E. A. W. (1902). The histories of Rabban Hormizd the Persian and Rabban Bar-Idta (Vol. 2). Londres: Luzac.

CÁCERES WÜRSIG, I. (mayo de 2000). La traducción en España en el ámbito de las relaciones internacionales, con especial referencia a las naciones y lenguas germánicas (s. XVI-XIX). (Tesis doctoral). Universidad Complutense, Madrid.

Carreño, A. M. (1963). Efemérides de la Real y Pontificia Universidad de México, según sus libros de claustros (Vol. 1). México: Universidad Nacional Autónoma de México.

D’Arvieux, L. (1735). Mémoires (Vol. 4). París: Charles Jean-Baptiste Delespine.

Farah, Caesar E. (Ed. y Trad.). (2003). An Arab's journey to Colonial Spanish America. The travels of Elias al-Musili in the seventeenth century. Syracuse, NY: Syracuse University Press.

FAROQHI, S. (2005). The Ottoman Empire and the world around it. Londres: I. B. Tauris.

Galí, M. (2001). El patrocinio episcopal en la ciudad de Puebla: el caso del obispo Manuel Fernández de Santa Cruz (1677-1699). En Actas III Congreso Internacional del Barroco Americano: territorio, arte, espacio y sociedad (pp. 71-90). Sevilla: Universidad Pablo de Olavide.

Gemayel, N., Saadé, I. y Khater, A. (abril de 1998). Miguel Casiri, impulsor del arabismo en España. Encuentro Islamo-Cristiano, 312, 1-12.

Ghobrial, J.-P. A. (2012). Stories never told: The first Arabic history of the New World. Osmanl Araştırmalar / The Journal of Ottoman Studies, (40), 259-282.

GHobrial, J.-P. A. (febrero de 2014). The secret life of Elias of Babilon and the uses of global microhistory. Past and Present, 222(1), 5193. http://www.dx.doi.org/10.1093/pastj/gtt024

GoKhale, B. G. (1979). Surat in the seventeenth century: A study in urban history of pre-modern India. Londres: Curzon Press.

Goodrich, T. D. (abril-junio de 1987). Tarihi-i Hind-i Garbi: An Ottoman Book on the New World. Journal of the American Oriental Society, 107(2), 317-319. http://www.dx.doi.org/10.2307/ 602841

Goodrich, T. D. (1990). The Ottoman Turks and the Nerw World: A study of Tarib-i Hind-i Garbi and sixteenth-century Ottoman Americana (N. S., Vol. 3). Wiesbaden: Otto Harrassowitz. 
Gregorian, V. (verano-otoño de 1974). Minorities of Isfahan: The Armenian community of Isfahan 1587-1722. Iranian Studies, $7(3-4), 652-680$.

GruZINSKI, S. (2015). ¡Qué hora es allá? América y el islam en los albores de la modernidad. (Trad. J. J. Utrilla). México: Fondo de Cultura Económica.

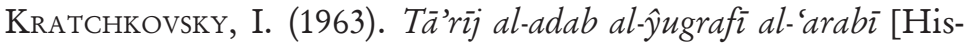
toria de la literatura geográfica árabe] (Vol. 2). (Trad. Șalāh alDīn 'Uțmān Hāšim). El Cairo: Laŷna l-Tālîf wa l-Tarŷama wa 1-Našr.

L'Audiance donnée par Sa majesté, a Soliman Mouta-Faraca, envoyé du Grand Seigneur: avec ce qui s'est passé en sont voyage. (1669). Gazette, (148), 1193-1200.

La sainte messe des Caldéens et des maronites du mont Liban, mise en françois, suivant le soubait de plusieurs personnes pieuses, et par l'ordre exprez de la Reine, lors que Sa Majesté voulut bien entendre celle que Dom Hissa Prestre Caldéen, celebra en Langue Syriaque, et avec les Ceremonies qui sont propres aux chrestiens de son pays, dans la Chapelle du Vieux Chasteau de S. Germain en Laye, le vingt-deuxiéme jour du mois d'Avril de l'an 1673. (1678). (Trad. Abad Morel). París.

La santa missa de los caldeos y de los maronitas, del monte Líbano. (1679). (Trad. Don Hissa). Bayona: Antonio Favuet.

La santa missa de los caldeos y de los maronitas del monte Líbano. (1701?). (Trad. D. Issa). Madrid: Imprenta de los Herederos de Antonio Román.

López de Velasco, J. (1894). Geografía y descripción universal de las Indias. Madrid: Establecimiento Tipográfico de Fortanet.

Lотн, O. (1877). A catalogue of the Arabic manuscript in the Library of the India Office. Londres: Stephen and Sons Printers.

Lunde, P. (mayo-junio de 1992a). A Muslim history of the New World. Aramco World, 43(3), 26-33.

Lunde, P. (mayo-junio de 1992b). The New World through Arab eyes. Aramco World, 43(3), 56-65.

Marín Guzmán, R. (2009). Un viaje poco conocido. La visita de Elías al-Marwsili, sacerdote caldeo iraquí, a la América Colonial (1669?1680). San José: Universidad de Costa Rica.

Marín GuZMán, R. (2011). El viaje del imam 'Abd al-Rabman ibn 'Abd Allah al-Baghdadi a Brasil en el siglo XIX. México: El Colegio de México.

Masters, B. (2001). Christians and Jeres in the Ottoman Arab World. Cambridge: Cambridge University Press. 
Matar, N. (1999). Turks, Moors, and Englishmen in the age of discovery. Nueva York, NY: Columbia University Press.

Matar, N. (Ed. y Trad.). (2003). Kitab Siyahat al-Khoury Illyas ibn al Quissees Hanna al-Mawsuli [The Book of Travels of the Priest Ilyas, Son of the Cleric Hanna al-Mawsuli]. En Autor. In the lands of Christians. Arabic travel writing in the seventeenth century (pp. 45-111). Nueva York, NY: Routledge.

MAzA, F. de la. (1963). Otra vez tres guerras. Anales del Instituto de Investigaciones Estéticas, 8(32), 53-58.

Mutafian, C. (1988). La Cilicie au carrefour des empires. París: Les Belles Lettres.

Paradela, N. (2005). El otro laberinto español. Viajeros árabes a España entre el siglo XVII y 1936. Madrid: Siglo XXI de España Editores.

Paz, O. (2004). Sor Juana Inés de la Cruz o las trampas de la fe. México: Fondo de Cultura Económica.

RABBĀṬ AL-YASƯ'ì, A. (Ed.) (1905). Riḥla awwal sā’ih šarqīi ilà Amrika [Ribla del primer viajero oriental a América]. Al-Machriq, 8(1824).

RABBĀṬ AL-YASŪ'İ, A. (Ed.) (1906). Riḅla awwal šarqĩ ilà Amrika, wahiya siyāha al-jūrù Ilyās ibn al-qissìs Hannā l-Maresilì min 'ayla bayt 'Ammūn al-kaldānī, 1668-1683 [Ribla del primer oriental a América, el viaje del cura Elías hijo del sacerdote Hannā l-Mawsilī de la familia caldea 'Ammūn]. Beirut: al-Maṭba'a al-Kātūlikiyya.

Rivera TANCo, L. (1883). Nuestra Señora de Guadalupe y origen de su milagrosa imagen (6a ed.). México: Imprenta y Litografía Española.

Robles, A. de. (1972). Diario de sucesos notables (1665-1703) (Vol. 2). México: Porrúa.

Rocha, D. A. (1891). Tratado único y singular del origen de los indios del Perú, Méjico, Santa Fe y Chile. (Vol. 1). Madrid: Tomás Minuesa.

Rubio Mañé, J. I. (2005). El virreinato (Vols. 1-2). México: Fondo de Cultura Económica.

Santa Maria, G. di. (1666). Prima speditione all Indie Orientali. Roma: Filippo Maria Mancini.

SAnta Maria, G. di. (1672). Seconda speditione all Indie Orientali. Roma: Filippo Maria Mancini.

Sarkisian, M. (1987). Armenians in South-East Asia. Crossroads: An Interdisciplinary Journal of Southeast Asian Studies, 3(2-3), 1-33.

SCHNurrer, C. F. von (1811). Bibliotheca Arabica. Halle: I. C. Hendel. SETH, M. J. (1897). History of the Armenians in India. From the earliest times to the present day. Londres: Luzac. 
TABOADA, H. (2011). Extrañas presencias en las Indias: acerca de los otros mediterráneos. Revista de Historia de América, (144), 43-69.

\section{Materiales de archivo}

Archivo General de Indias (España), Contratación, leg. 5440, N. 2, R. 135.

Archivo General de la Nación (México), Instituciones coloniales/

Regio Patronato Indiano/Universidad (114), vol. 17.

\section{Anexo: Cronología}

1668 Ilyās parte de Bagdad para Jerusalén. Se embarca en Iskenderun en un barco inglés para Europa.

Llega a Venecia, luego se dirige a Roma y recibe del papa Clemente IX cartas para su viaje.

Viaja a Francia, sale del puerto de Marsella y llega a Aviñón, luego a Lyon, donde reencuentra al excónsul de Francia en Alepo, François Picquet. Después se dirige a París y es recibido por el rey Luis XIV; luego visita al duque de Orleans y al duque de Saint-Aignan.

1669 Permanece en París como intérprete de Solimán Aga, enviado del sultán otomano Mehmed IV ante el rey de Francia.

De París viaja a España, pasa por Burgos y luego llega a Madrid.

Se dirige a Barcelona y viaja por mar a Tolón, luego va a Roma. Después se dirige a Nápoles y a Palermo.

Regresa a España vía Roma. Luego va a Portugal y regresa a Madrid.

1675 (12 de febrero). Sale de Cádiz hacia América.

Pasa por una de las islas Canarias con dirección a Caracas y luego a la isla Margarita, llega al puerto de Cumaná, luego a Curazao y más tarde a isla Tortuga.

Después de 55 días llega a Cartagena y luego a Santa Fe. Después llega a San Felipe de Portobelo y pasa a Panamá, de ahí va a Guayaquil, luego a Quito y a Cuenca.

Después se dirige a Piura y luego a Trujillo.

1677 Llega a Lima, viaja a Huancavélica y llega a la villa imperial de Potosí.

1679 Arriba a Plata (Sucre), en Bolivia. 
1680 Regresa a Lima, vía El Callao. Empieza a escribir el relato de su viaje.

1681 (21 de septiembre). Sale de Perú rumbo a Panamá para dirigirse a la Nueva España; pasa por el puerto de El Realejo, Nicaragua, San Salvador, Guatemala, Ciudad Real de Chiapa, Antequera Oaxaca y Puebla de los Ángeles.

1682 (8 de julio). Entra en la Ciudad de México.

1684 (18 de noviembre). Sale del puerto de Veracruz. Llega a La Habana y permanece ahí cuatro meses y medio.

1685 (¿23 de mayo?). Sale de La Habana rumbo a Cádiz.

1685 (16 de junio). Arriba a Cádiz y se dirige a Sevilla. Luego regresa a Cádiz para embarcarse en un navío holandés hacia Roma, con dos sirvientes armenios.

1686 Llega a Roma y es recibido por el papa Inocencio XI (papado 1676-1689).

1688 (Marzo). Actúa como representante en Roma del obispo de Arequipa (Perú), Antonio de León y Becerra (obispado de Panamá, 1672-1676; obispado de Arequipa, 1677-1711), al que había conocido en su estancia en Panamá y luego rencontrado en su paso por Arequipa (Ghobrial, 2014, p. 85).

1691 (Octubre). Solicita una audiencia con el papa Inocencio XII (papado 1691-1700) (Ghobrial, 2014, p. 85).

1692 Se publica en Roma, a su costa, un libro de oraciones en árabe y en latín.

1694 Se le menciona por última vez en los documentos de la Propaganda Fide, con el señalamiento de que vivía en España (Ghobrial, 2014, p. 85).

1699 Mantiene un pleito mercantil con Juan de Zalaeta por 142 pesos; se le menciona como vecino del Puerto de Santa María en Sevilla. En el documento de este caso aparece el nombre de don Andrés de San Juan, a quien don Elías se refiere como "mi sobrino [...] e intérprete de Su Majestad en la corte de Madrid" (Ghobrial, 2014, p. 91). Se trata, en efecto, del hijo de su hermano 'Abd Allāh, Andrāws ibn Maqdisī 'Abd Allāh, quien había colaborado, como mencioné, con don Elías en la edición árabe latina del libro de oraciones publicado en 1692. A este sobrino se debe también la copia más antigua del viaje de don Elías, la cual, como se desprende del colofón, fue "concluida [...] en el puerto de Santa María de mano del humilde caballero Andrāws ibn Maqdisī 'Abd Allāh al-Kaldānī el primer día del bendito mes de marzo del año de 1669" (Loth, 1877, p. 207; Ghobrial, 2012, p. 266; Ghobrial, 2014, p. 90). 